\title{
Amelioration of Diabetic Nephropathy Using a Retinoic Acid Receptor $\beta 2$ Agonist $\mathbf{s}$
}

\author{
Steven E. Trasino, Xiao-Han Tang, Maria M. Shevchuk, Mary E. Choi, \\ and Lorraine J. Gudas
}

\begin{abstract}
Departments of Pharmacology (S.E.T., X.-H.T., L.J.G.) and Pathology (M.M.S.) and Division of Nephrology and Hypertension, Department of Medicine (M.E.C.), Weill Cornell Medical College of Cornell University, School of Urban Public Health, Nutrition Program, Hunter College, City University of New York (S.E.T.), and NewYork-Presbyterian Hospital-Weill Cornell Medical Center (M.E.C.), New York, New York
\end{abstract}

Received March 27, 2018; accepted July 20, 2018

\begin{abstract}
Vitamin $\mathrm{A}(\mathrm{VA})$ and its derivatives, known as retinoids, play critical roles in renal development through retinoic acid receptor $\beta 2$ (RAR 32 ). Disruptions in VA signaling pathways are associated with the onset of diabetic nephropathy (DN). Despite the known role of RAR $\beta 2$ in renal development, the effects of selective agonists for RAR $\beta 2$ in a high-fat diet (HFD) model of DN are unknown. Here we examined whether AC261066 (AC261), a highly selective agonist for RAR $\beta 2$, exhibited therapeutic effects in a HFD model of DN in C57BL/6 mice. Twelve weeks of AC261 administration to HFD-fed mice was well tolerated with no observable side effects. Compared with HFD-fed mice, HFD + AC261-treated mice had improved glycemic control and reductions in proteinuria and urine albumin-to-creatinine ratio. Several cellular hallmarks of DN were mitigated in HFD + AC261-treated
\end{abstract}

mice, including reductions in tubule lipid droplets, podocyte (POD) effacement, endothelial cell collapse, mesangial expansion, and glomerular basement membrane thickening. Mesangial and tubule interstitial expression of the myofibroblast markers $\alpha$-smooth muscle actin ( $\alpha$-SMA) and type IV collagen (Col-IV) was lower in HFD + AC261-treated mice compared with HFD alone. Ultrastructural and immunohistochemistry analyses showed that, compared with HFD-fed mice, HFD + AC261-treated mice showed preservation of POD foot process and slit-diaphragm morphology, an increase in the levels of slit-diagram protein podocin, and the transcription factor Wilms tumor-suppressor gene 1 in PODs. Given the need for novel DN therapies, our results warrant further studies of the therapeutic properties of AC261 in DN.

\section{Introduction}

Diabetic nephropathy (DN) is the most common cause of end-stage renal disease (de Boer et al., 2011) and the single strongest predictor of mortality from cardiovascular disease in patients with type 2 diabetes (T2D) (Stratton et al., 2000; Valmadrid et al., 2000). Clinically, DN is characterized by the onset of glomerular lesions, progressive loss of glomerular filtration rate, albuminuria, and hypertension (Tervaert et al., 2010). Intervention trials have demonstrated that intensive glycemic and hypertension control for DN has limited therapeutic effectiveness (Parving et al., 2012; Fried et al., 2013; Gentile et al., 2014; Hajhosseiny et al., 2014). Thus, given the

This research was supported in part by Weill Cornell funds and the National Institutes of Health (NIH) National Institute of Diabetes and Digestive and Kidney Diseases [R01 DK113088] and the NIH National Cancer Institute [T32 CA062948]

https://doi.org/10.1124/jpet.118.249375.

S This article has supplemental material available at jpet.aspetjournals.org. limitations of current DN therapies, there is an urgent need to identify molecules that can therapeutically modulate relevant kidney cell types and pathways central to the pathogenesis of DN (Gentile et al., 2014).

Vitamin A (VA, retinol) is an essential micronutrient that, acting primarily through its biologically active metabolite alltrans-retinoic acid (RA) and RA receptors $(\operatorname{RAR} \alpha, \beta$, and $\gamma$ ), regulates the expression of genes that are vital to reproduction, organogenesis, and adult human health (Chambon, 1996; Gudas, 2012). Normal kidney development is highly dependent on RA signaling (Gilbert, 2002), as the severe renal malformations and reduced numbers of nephrons that occur in VA-deficient newborn mice can be reversed with exogenous RA (Lelièvre-Pégorier et al., 1998). In developing kidney rudiments, RA is synthesized locally (Rosselot et al., 2010; Gudas, 2012) and, acting through $\operatorname{RAR} \alpha$ and $\operatorname{RAR} \beta 2$, modulates the expression of the receptor tyrosine kinase and c-ret (Ret) (Batourina et al., 2001, 2002; Rosselot et al., 2010), which directs nephron differentiation and branching of the ureteric

ABBREVIATIONS: $\alpha$-SMA, $\alpha$-smooth muscle actin; AC261, AC261066, a retinoic acid receptor $\beta 2$ selective agonist; ACR, albumin-to-creatinine ratio; Aldh1a2, aldehyde dehydrogenase, member 1a2; BW, body weight; CKD, chronic kidney disease; Crbp1, cellular retinol binding protein 1; Cyp26a1, cytochrome P450, member 2a1; DMSO, dimethylsulfoxide; DN, diabetic nephropathy; EC, endothelial cell; GBM, glomerular basement membrane; GFB, glomerular filtration barrier; HFD, high-fat diet; HPLC, high-performance liquid chromatogtaphy; IHC, immunohistochemistry; LD, lipid droplet; PAS, periodic acid-Schiff; POD, podocyte; qPCR, quantitative polymerase chain reaction; RA, retinoic acid; RAR, retinoic acid receptor; RBP4, retinol binding protein-4; RC, renal cancer; ROL, retinol; STRA6, stimulated by retinoic acid 6; T2D, type 2 diabetes; TEC, tubule epithelial cell; TEM, transmission electron microscopy; VA, vitamin A; WT, wild-type; WT1, Wilms tumor-suppressor gene 1. 
bud (Batourina et al., 2001). Through a highly conserved retinoic acid responsive element, $\mathrm{RA}-\mathrm{RAR} \beta 2$ also regulates expression of Wilms tumor-suppressor gene 1 (WT1) (Bollig et al., 2009), a master transcriptional regulator of glomerular cell development (Kreidberg et al., 1993; Palmer et al., 2001). Mice that lack $\mathrm{RAR} \beta 2$ or $\mathrm{RAR} \alpha$ exhibit severe renal malformations and reduced kidney mass and nephron numbers (Mendelsohn et al., 1999).

In the adult kidney, cells in the glomerulus and tubule epithelial cells are responsible for VA-retinol binding protein-4 (RBP4) recycling (Blomhoff et al., 1990; Raila et al., 2005); as such, perturbations in VA-RBP4 homeostasis have been observed in DN (Smith and Goodman, 1971; Raila et al., 2007; Frey et al., 2008). Despite the well established role of the kidney in maintenance of whole body VA homeostasis (Blomhoff et al., 1990; Raila et al., 2005), the molecular actions of VA, RA, and the RARs on renal parenchymal cell functions are still emerging. However, a convincing body of data demonstrates that VA, acting through RA, shows protective properties in several renal diseases (Lazzeri et al., 2014; Mallipattu and He, 2015), such as experimental glomerulonephritis (Wagner et al., 2000; Schaier et al., 2001; Lehrke et al., 2002; Perez et al., 2004; Chiba et al., 2016), HIV-associated nephropathy (Lu et al., 2008; Ratnam et al., 2011), and DN (Han et al., 2004; Kim et al., 2015).

Perturbations in renal VA metabolism and RA signaling appear to be involved in the onset of $\mathrm{DN}$, as reductions in renal VA metabolism and RA signaling occur in mouse and human T2D-DN (Raila et al., 2007; Frey et al., 2008; Starkey et al., 2010; Trasino et al., 2015; Jing et al., 2016), and albuminuria promotes progression of renal injury by inhibiting RA-mediated differentiation of podocyte progenitors (Peired et al., 2013). It is well established that RA favorably modulates the functions of several cell types vital to the glomerular filtration barrier (Anderson et al., 1998; Vaughan et al., 2005; Su et al., 2012; Zhang et al., 2012), and as such, pharmacological approaches that increase podocyte responsiveness to RA signaling mitigate progression of experimental renal injury (Sagrinati et al., 2006; Lasagni et al., 2015). Given the aberrant renal metabolism of VA and RA in T2D and DN (Trasino et al., 2015), a novel approach for development of retinoid-mediated DN therapies is the use of synthetic agonists for RARs, as they are not as likely to be affected by altered VA metabolism that occurs in T2D-DN (Starkey et al., 2010; Trasino et al., 2015; Jing et al., 2016). RAR $\beta$ is expressed predominantly in glomerular cells in the adult kidney (Manzano et al., 2000; Zhong et al., 2011; Uhlén et al., 2015), and RAR $\beta 2$ is the most relevant $\operatorname{RAR} \beta$ isotype in renal development (Batourina et al., 2001). Thus, we tested the anti-DN properties of an orally available agonist selective for RAR $\beta 2$ (AC261066) (Lund et al., 2005, 2009), which we previously demonstrated possesses antidiabetic properties in murine models of obesity and T2D (Trasino et al., 2016a,b). To date, studies of the renal protective properties of RA- or RAR-specific agonists have not used high-fat dietary (HFD) models of DN (Wei et al., 2004; Brosius et al., 2009; Deji et al., 2009); therefore, in light of our previous work demonstrating the anti-T2D properties of AC261066 in HFD-models of T2D (Trasino et al., 2016a,b), in the current study we examined whether AC261066 possesses renal protective properties in a HFD model of DN.

\section{Materials and Methods}

HFD Model of DN and Drug Treatments. All animal experiments were conducted in accordance with the Guide for the Care and Use of Laboratory Animals as adopted and promulgated by the U.S. National Institutes of Health and the Institutional Animal Care and Use Committee guidelines at Weill Cornell Medical College. A HFDfed C57BL/6 mouse model of DN was used for this study, as this model results in obesity, insulin resistance, and renal injury; the renal injury exhibits several features of human DN, including microalbuminuria, podocytopenia, glomerular hypertrophy, basement membrane thickening, mesangial expansion, and renal lipid accumulation (Brosius et al., 2009; Deji et al., 2009).

Wild-type (WT), 10-week-old, male C57BL/6 mice fed a standard laboratory chow (13\% kcal fat, no. 5053; Pico Diet, St. Louis, MO) were randomized to either remain on a laboratory chow (control, $n=4$ ) or a high-fat, DN diet (HFD, $n=8$ ) (45\% kcal fat, no. 58125; Test Diets, St. Louis, MO) for 16 weeks. Four weeks after beginning HFD treatment, HFD groups were further randomized to: 1) remain on the HFD diet, plus drinking water containing $0.2 \%$ DMSO (HFD, $n=4)$ or 2 ) the HFD diet, plus drinking water containing $3.0 \mathrm{mg} / 100 \mathrm{ml}$ of AC261066 (AC261) [in 0.2\% DMSO (HFD + AC261, $n=4$ )], a highly selective, orally bioavailable RAR $\beta 2$ agonist (Lund et al., 2005) for 12 weeks. At the end of the study, mice from all groups were subjected to intraperitoneal glucose tolerance testing as previously described (Trasino et al., 2016b) and spot urine analysis (Kurien and Scofield, 1999); then mice were sacrificed for tissue harvesting and analysis.

Renal Histology Analysis from BKS-db/db Mice. Renal tissue samples from 16-week-old male C57Bl/6 BKS-db/db mice Cg-Dock $7^{\mathrm{m}}+/+$ $\mathrm{Lepr}^{\mathrm{db}} / \mathrm{J}$ (BKS-db, stock no. 000642) mice (Jackson Laboratories, Bar Harbor, ME) were evaluated to determine the effects of AC261 on renal histologic markers of DN. BKS-db/db mice spontaneously develop severe insulin resistance by 4 to 5 weeks of age (Hummel et al., 1966) and are frequently used as a DN model because they develop a numerous renal histologic features of DN, including glomerulosclerosis, podocytepenia, and mesangial expansion (Sharma et al., 2003). Fourteen-week-old male BKS-db/db mice were maintained on standard laboratory chow (Con) with $13 \%$ kcal fat (no. 5053; Pico Diet) and randomized to receive 1) drinking water containing $0.2 \%$ DMSO or 2) drinking water containing $3.0 \mathrm{mg} / 100 \mathrm{ml}$ of AC261 (in $0.2 \%$ DMSO) for 14 days.

Morning Spot Urine Analysis. For determination of albuminuria, morning urine samples were obtained as previously described (Kurien and Scofield, 1999) on a single urine collection from two experimental cohorts of control mice $(n=5)$, HFD-fed mice $(n=5)$, and HFD-fed mice treated with AC261 $(n=3)$ as described above. Urine samples were centrifuged at $10,000 \mathrm{~g}$ for 3 minutes at $4^{\circ} \mathrm{C}$ to remove cellular debris and stored at $-70^{\circ} \mathrm{C}$ until analysis. Urine samples were analyzed for albumin and creatinine using mouse albumin enzymelinked immunosorbent assay (Molecular Innovations, Novi, MI) and mouse creatinine enzyme-linked immunosorbent assay kits (BioAssay Systems, Hayward, CA) respectively, according to the manufacturer's instructions. To ensure that differences in urine volumes would not affect the albuminuria analyses, we compared creatinine normalization of urine albumin levels with urine-specific gravity (osmolality, mOsm) and normalized urine albumin levels and had similar findings.

Immunohistochemistry. Renal tissue samples were fixed and processed for immunohistochemistry (IHC) as previously described (Trasino et al., 2016b). Deparaffinized kidney tissue sections were incubated with the following antibodies overnight at $4^{\circ} \mathrm{C}$ : podocin (goat anti-mouse, IgG 1:200, sc-22298; Santa Cruz, Dallas, TX), WT1 (rabbit anti-mouse, IgG 1:100, sc-192; Santa Cruz), smooth muscle actin- $\alpha$ ( $\alpha$-SMA) (mouse anti-mouse, monoclonal IgG1, 1:500, clone 1A4; Dako, Santa Clara, CA), and collagen IV (rabbit anti-mouse, IgG 1:200, NB120-6586; Novus Biologicals, Littleton, CO). After incubation with secondary antibodies (Super Picture polymer detection kit; Invitrogen Corp., Carlsbad, CA), signals were visualized based on a peroxidase detection mechanism with a 3,3-diaminobenzidine (DAB) substrate. 
Quantitation of DAB IHC. For quantitation of IHC of renal podocin, WT1, $\alpha$-SMA, and collagen IV, analysis was performed using four to five DAB-positive fields per slide, with three to four slides per mouse ( $7 \mu \mathrm{m}$ between each slide sections), and three to four mice per group, for a total of 40 to $50 \mathrm{DAB}$-positive fields per experimental group. DAB-positive slide fields were photographed using a Nikon TE2000-inverted light microscope and digital images were analyzed for DAB densitometry by color deconvolution using Fiji, ImageJ software as described (Schindelin et al., 2012).

Glomerular Area Studies. We stained paraffin-embedded kidney sections with H\&E and periodic acid-Schiff (PAS) using standard histology protocols for histopathology evaluation (Tervaert et al., 2010). We performed glomerular area studies as described (Krendel et al., 2009). Digital images of H\&E-, PAS-stained kidney sections were analyzed for mean glomerular area and PAS densitometry using Fiji ImageJ software (Schindelin et al., 2012), 50-60 glomeruli per animal (with four animals per experimental group), were used to determine mean glomerular area in the HFD-DN and BKS-db/db DN mouse cohorts.

Renal Histopathology. Renal sections were separately analyzed by a pathologist and nephrologist in a blinded manner and classified according to DN histopathologic classification (Tervaert et al., 2010). For each kidney sample, 40-50 H\&E- and PAS-stained cross-sections of glomeruli were analyzed and scored using the following scoring system: 0 , normal glomerulus; +1 , mesangial matrix expansion of the glomerulus; +2 , severe mesangial matrix expansion; +3 , severe mesangial matrix expansion and/or segmental glomerulosclerosis; and +4 , global glomerulosclerosis ( $>50 \%$ of the glomerulus). The mean glomerular score for each mouse was averaged for each treatment group. Interstitial damage was assessed with respect to interstitial fibrosis as described (Sastre et al., 2013).

Transmission Electron Microscopy Analysis of Glomerular Ultramorphologic Lesions. We processed fresh kidney samples for transmission electron microscopy (TEM) as described (Szeto et al., 2017). Freshly isolated renal tissue was fixed in $4 \%$ paraformaldehyde, followed by postfixation in $1 \%$ osmium tetroxide, dehydration in graded alcohols, and embedding in Epon. Ultrathin sections (200-400 A) were cut on nickel grids, stained with uranyl acetate and lead citrate, and examined in the Weill Cornell Microscopy Core using a digital transmission electron microscope (JEM-1400; JEOL, Ltd., Akishima, Japan).

We evaluated renal TEM sections for the following ultramorphologic changes: 1) diffuse glomerular basement membrane (GBM) thickening, 2) mesangial expansion, 3) podocytopenia, 4) diffuse foot process effacement, 5) electron-dense areas of hyalinosis in sclerotic nodules, 6) cellular lipid droplets (LDs), and 7) diabetic fibrillosis. We performed quantitative analysis of GBM thickening using the orthogonal intercept method of Jensen (Jensen et al., 1979). Briefly, 10 digital images were captured per animal (five capillary loops per glomerulus, five glomeruli per animal). A grid mask with intercepts was applied to each image, and GBM thickness was measured in pixels at each intercept from the basal endothelial to the basal podocyte plasma membranes and converted to nanometers using the image processing software iTEM (Olympus-SiS, Münster, Germany). Quantitative analysis of mesangial expansion (volume density of mesangium and mesangial matrix) was conducted as described in Guo et al. (2005), podocyte number as in Weibel and Gomez (1962), and diffuse foot process effacement according to Deegens et al. (2008). We evaluated and quantitated ultramorphologic changes to renal TEM sections in a blinded manner as described (Weibel and Gomez, 1962; Jensen et al., 1979; Guo et al., 2005; Deegens et al., 2008).

RNA Isolation and Quantitative RT-PCR. We extracted total RNA from renal cortex tissue preserved in RNA later (Thermo Scientific, Inc.) using the TRIzol reagent (Thermo Fisher Scientific, Waltham, MA.) from 6- to 8-week-old WT male C57BL/6 mice fed either a standard laboratory chow (control, 13\% kcal fat, no. 5053; Pico Diet, $n=4$ ); a HFD, $45 \%$ kcal fat, no. 58125; Test Diets, $n=4$ ) for $\sim 14$ weeks; or a HFD diet for 9 weeks, followed by a HFD but with drinking water containing $3.0 \mathrm{mg} / 100 \mathrm{ml}$ of AC261066 (AC261) (in $0.2 \%$ dimethylsulfoxide, DMSO) (HFD $+\mathrm{AC} 261, n=4)$ for 5 weeks. Total RNA ( $1 \mu \mathrm{g})$ was used to synthesize cDNA using the Revert Aid First Strand cDNA Synthesis Kit (Thermo Scientific, Inc.). We performed quantitative RT-PCR (q-PCR) as previously described (Trasino et al., 2016b) using SYBR Green PCR master mix on an Agilent Mx3000P realtime PCR system (Agilent Technology, Inc., Waltham, MA). We used gene-specific primers (Supplemental Table 1) to amplify mRNAs that were then normalized to the internal control gene, hypoxanthine phosphoribosyltransferase $(\mathrm{Hprt})$. cDNA from four mice $(n=4)$ per experimental group was analyzed for relative mRNA fold changes. We calculated relative gene expression fold changes using the $\Delta, \Delta \mathrm{Ct}$ method (Livak and Schmittgen, 2001).

High-Performance Liquid Chromatography of Renal and Serum Vitamin A (Retinol). Retinol (ROL) was extracted from renal and serum samples using acetonitrile:butanol (50:50, v/v), 0.1\% butylated hydroxytoluene, and saturated $\mathrm{K}_{2} \mathrm{HPO}_{4}$ and analyzed by high-performance liquid chromatography (HPLC) as previously described (Trasino et al., 2015). ROL was identified in tissue samples based an exact match of the retention times of peaks of pure ROL standards and its UV absorption spectrum. The concentration of the ROL standard was used to calculate ROL concentrations normalized to milligrams of wet renal tissue weight or volume for serum.

Statistics. All data means were tested and passed normality testing using Shapiro-Wilk normality test (GraphPad Software, Inc., San Didego, CA). Group means for data in Fig. 1, E and F (spot urine analysis and ACR, IHC for $\alpha$-SMA and collagen IV) were computed using analysis of variance and Bonferroni's multiple comparison test, with group means treated as independent variables owing to having fewer than $n=4$ per experimental group. Means testing from all other figures were analyzed using repeated measures analysis of variance and Bonferroni's multiple comparison test. Group means for all figures are reported as mean \pm S.D. The number of mice used for each analysis is indicated in the relevant methods sections and figure legends. Significant differences were defined as $P$ values with an $\alpha<0.05$, and all use of the term significant throughout this article refers to means differences with a $P<0.05$. All statistical analyses were performed using GraphPad Prism 7.0 statistical software (GraphPad Software, Inc.).

\section{Results}

Treatment with an RARß2 Agonist Improves Renal Injury and Urine Albumin Excretion in HFD-Fed Mice. Sixteen weeks of HFD feeding led to a $50 \%$ increase in body weights (BW) (Fig. 1A) and resulted in impaired glucose tolerance compared with chow-fed (control) mice (Fig. 1, B-D). Treatment with AC261 had no effect on BW (Fig. 1A) but, as previously reported, partially restored euglycemia in the HFD + AC261 mice (Fig. 1, B-D) (Trasino et al., 2016b).

Sixteen weeks of HFD feeding resulted in an increase of $\sim 522 \%$ in urine albumin excretion and $\sim 187 \%$ increase in urine albumin-to-creatinine ratio (ACR) (Fig. 1, E and F). HFD + AC261-treated mice showed $50 \%$ and $40 \%$ lower levels of urine albumin and ACR, respectively, compared with HFD alone (Fig. 1, E and F). As previously reported, AC261 treatment did not affect water or food intake (not shown) (Trasino et al., 2016b).

RARß2 Agonist Treatment Results in Less Tubule Vacuolization and Glomerular Hypertrophy. The patterns of renal lipid accumulation in the HFD-fed cohort (Fig. 2A, b, yellow arrows) agree with those observed in human DN (Bobulescu et al., 2014; Herman-Edelstein et al., 2014) and murine diet-induced models of T2D (Bobulescu, 2010), with the appearance of tubule epithelial cell (TEC) vacuolization, 


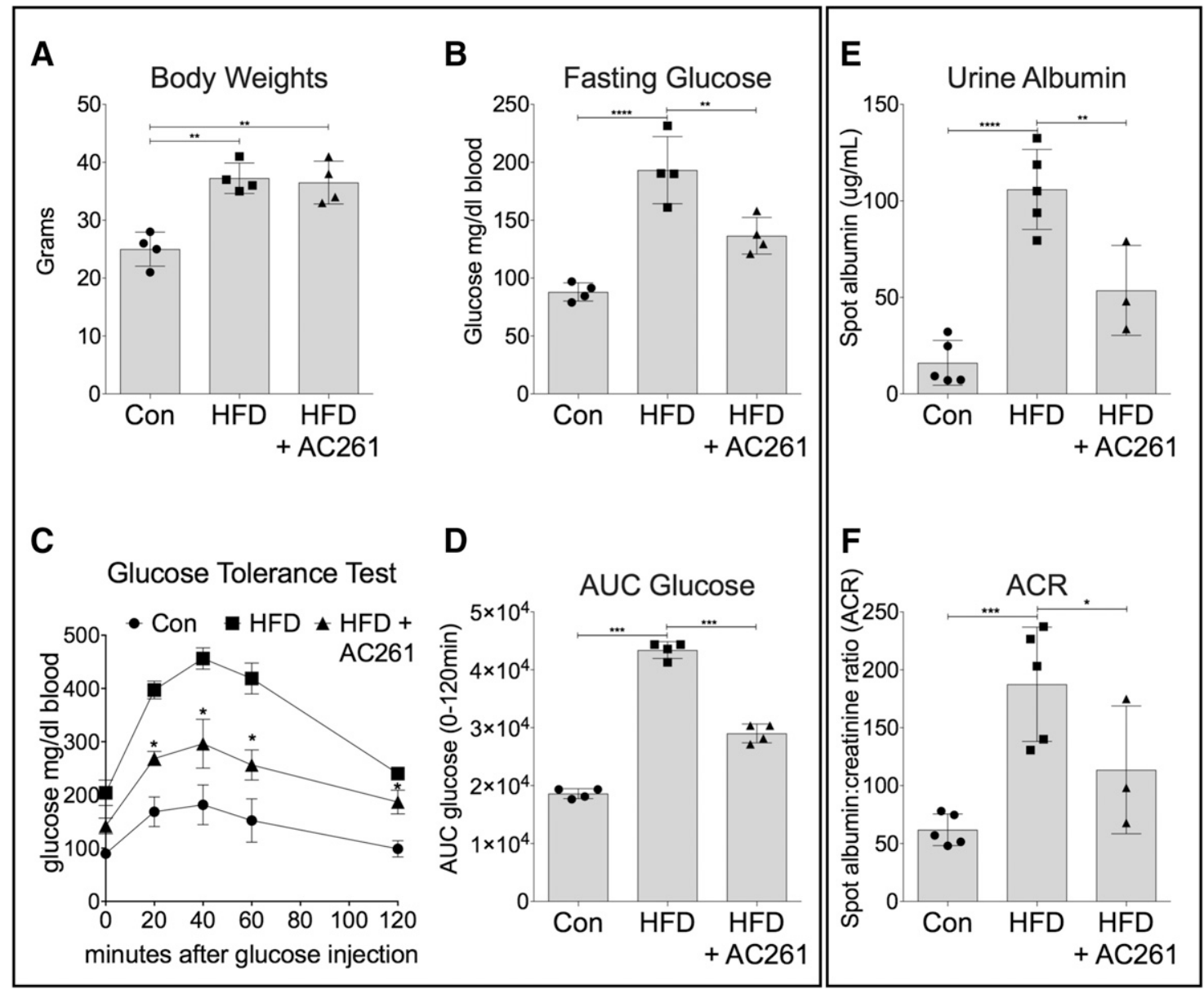

Fig. 1. Effects of AC261066 (AC261), a RAR $\beta 2$ agonist, on glucose tolerance and urine albumin excretion in a HFD model of diabetic nephropathy. (A) Body weights of C57BL/6 WT male mice after 16 weeks of being fed either a standard control chow (13\% kcal fat) diet (Con, $n=4)$, a HFD (45\% kcal fat) ( $n$ = 4), or a HFD with the RAR 32 agonist AC261066 (HFD + AC261, $n=4$ ) in their drinking water from week 5 to week 16. (B) Fasting glucose levels in mice from (A). (C) Glucose tolerance tests (GTT) and (D) area under the curve (AUC) glucose in mice from (A). (E) Spot morning urine albumin concentration $(\mu \mathrm{g} / \mathrm{ml})$ and $(\mathrm{F})$ spot morning (ACR) in mice as described in Materials and Methods, with control mice $(n=5) ;(\mathrm{HFD}, n=5)$ and $(\mathrm{HFD}+\mathrm{AC} 261, n=3)$. Error bars represent \pm S.D. of the mean with $* P<0.05 ; * * P<0.01 ; * * * P<0.001 ; * * * P<0.0001$.

a marker of cytosolic LDs and impaired TEC lipid metabolism (Tervaert et al., 2010; Kang et al., 2015). We detected a 2.5- to 3.0-degree higher TEC vacuolization in HFD-fed mice compared with controls (Fig. 2A, b vs. a, yellow arrows; Fig. 2B, **P $P 0.01$ ) and a significant reduction in tubule vacuolization in HFD + AC261-treated mice compared with HFD-fed mice (Fig. 2A, c vs. b, yellow arrows; Fig. $2 \mathrm{~B},{ }^{*} P<0.05$ ). Consistent with the renal pathology in early human DN (Alsaad and Herzenberg, 2007), PAS- and H\&E-stained renal sections of HFD-fed mice compared with controls showed mild, diffuse expansion of glomerular mesangial matrix (Fig. 2C, PAS, b vs. a; Fig. $2 \mathrm{D} \sim 2.0$-fold, $* * * P<0.001$ ) extending into capillary loop membranes (Fig. 2C, PAS, b vs. a, yellow arrows). HFD-fed mice had marked glomerular hypertrophy (Fig. 2C, H\&E, d vs. e) and a significantly increased mean glomerular area compared with controls (Fig. $2 \mathrm{E}, * * * P<0.001$ ). Compared with HFD-fed mice, HFD + AC261-treated mice showed less accumulation of PAS-positive material in the mesangium (Fig. 2C; PAS, c vs. b; Fig. $2 \mathrm{D}$, $* * P<0.01$ ) and in capillary loop membranes (Fig. 2C, PAS, c vs. b, yellow arrows); consistent with this, there was less glomerular hypertrophy and a lower mean glomerular area (Fig. 2C, H\&E, f vs. e; Fig. $2 \mathrm{E},{ }^{*} P<0.05$ ).
Lower Expression of $\alpha$-Smooth Muscle Actin and Collagen IV with the RARß2 Agonist Treatment. Mesangial cells secrete extracellular matrix proteins, including type IV collagen, laminins, fibronectin, and various proteoglycans, which provide the functional and structural integrity of the glomerular tuft, including its capillary network (Couchman et al., 1994). In DN and chronic kidney disease, in response to injury glomerular and interstitial mesangial cells dedifferentiate to "mesangiocytes" and synthesize $\alpha$-SMA and other contractile proteins that contribute to glomerulosclerosis and DN progression (Cook, 2010). Our previous studies have demonstrated that AC261 treatments can reduce liver myofibroblast activation and expression of $\alpha$-SMA in a murine HFD model of nonalcoholic fatty liver disease (Trasino et al., 2016a). Therefore, we determined the effects of AC261 on renal $\alpha$-SMA protein expression by IHC.

In kidneys from control mice, TEC interstitial and glomerular $\alpha$-SMA protein staining was very weak (Fig. 3A, a, red arrow, inset), but, as expected, staining was prominent around arterioles (Fig. 3A, a, black arrow, inset). In contrast, in HFD-fed mice, compared with controls, we detected $\alpha$-SMA protein within glomeruli (Fig. 3A ,b vs. a; Fig. 3B, ${ }^{* * *} P<0.001$ ) and in the tubule interstitium (Fig. 3A, b vs. a, 
A
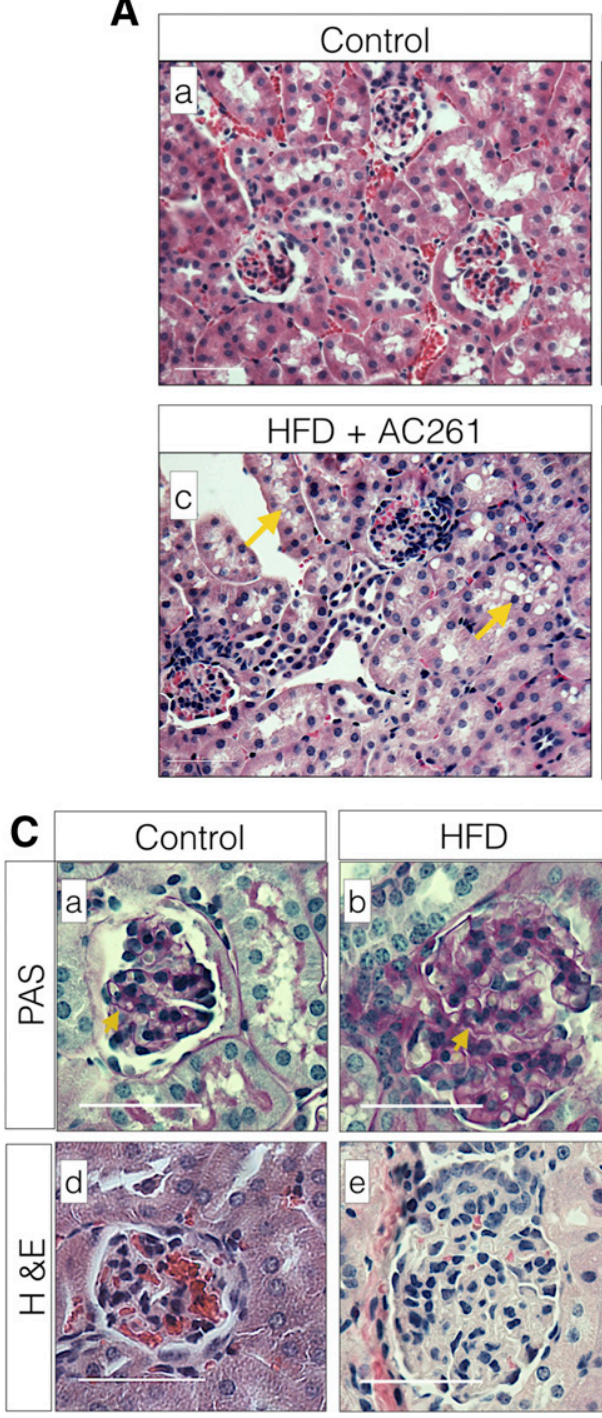
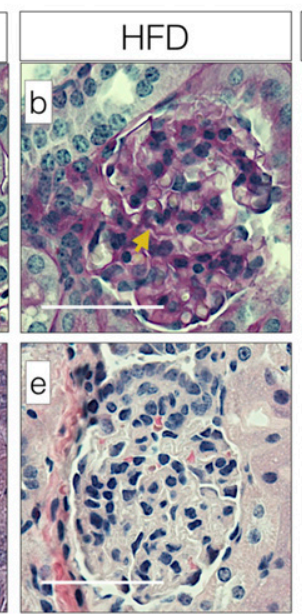
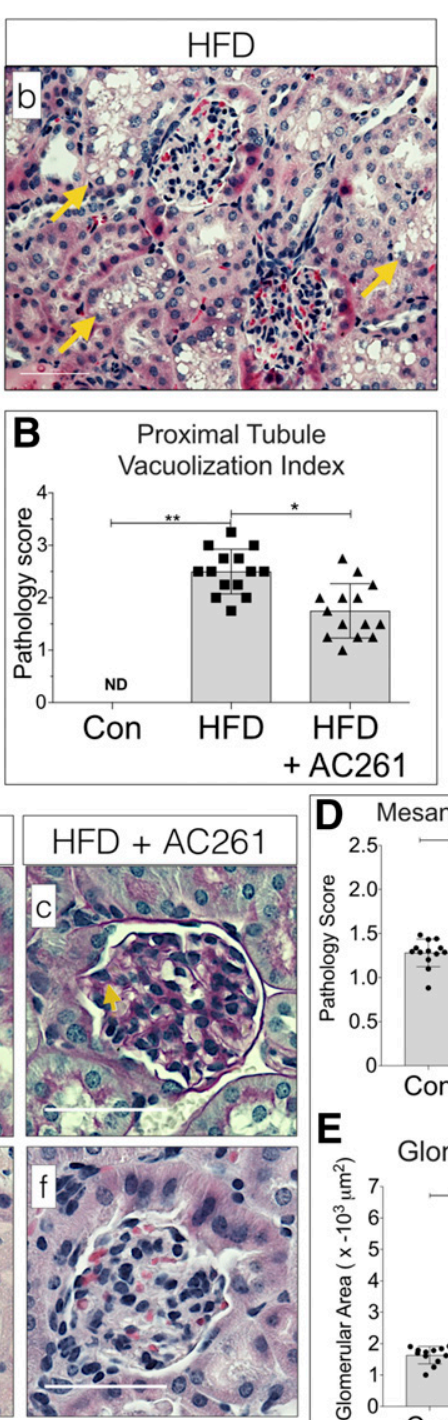

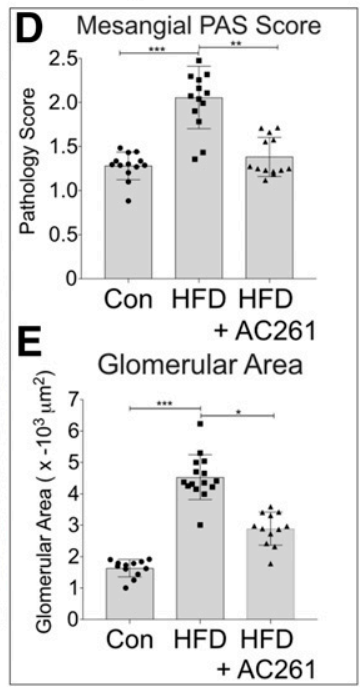

Fig. 2. RAR $\beta 2$ agonist results in less tubule lipid droplet (LD), mesangial expansion, and glomerular hypertrophy. (A) (a-c) Representative images of $\mathrm{H} \& \mathrm{E}$-stained renal tissue analyzed by light microscopy showing glomeruli and tubule $\mathrm{LD}$ vacuolization [b and c, yellow arrows], in mice described in Fig. 1A and analyzed with control mice $(n=4)$; (HFD, $n=4)$; and $($ HFD + AC261, $n=4)$. Original magnification, $100 \times$; scale bar, $50 \mu \mathrm{m}$. (B) Tubule vacuolization histology score of all mice from (A) and as described in Materials and Methods (ND = not detected). (C) Representative images of PAS [a-c; yellow arrows, a-c; capillary GBM thickening, and H\&E-stained $(\mathrm{d}-\mathrm{f})$ glomeruli] in all mice from (A). (Original magnification, $400 \times$; scale bar, $100 \mu \mathrm{m}$. (D) Mesangial expansion histology score of all mice from (A) and as described in Materials and Methods. (E) Mean glomerular area $\left(-10^{3} \mu \mathrm{m}^{2}\right)$ of all mice from (A) and as described in Materials and Methods. Histogram individual data points represent the score of each slide analyzed per mouse as described in Materials and Methods. Errors bars represent \pm S.D. of the mean of each group with $* P<0.05$; $* * P<0.01 ; * * * P<0.001$. red arrows, inset). Compared with HFD-fed mice, the interstitial $\alpha$-SMA protein level in HFD + AC261 mice was lower (Fig. 3A, c vs. b, red arrows, inset), and intraglomerular $\alpha$-SMA protein was also lower (Fig. 3A, c vs. b; Fig. 3B, $* * * P<0.001)$. Despite the increased expression of $\alpha$-SMA in HFD-fed mice (Fig. 3A, b) and consistent with murine models DN (Brosius et al., 2009), our HFD experiments did not result in glomerular or tubulointerstitial fibrosis (not shown).

We also measured the levels of collagen IV protein, a major contributor to glomerular expansion in $\mathrm{DN}$ and renal disease (Couchman et al., 1994), and found, consistent with the mesangial expansion (Fig. 2D) and the increased glomerular and interstitial $\alpha$-SMA (Fig. 3A, b), that HFD-fed mice exhibited a 0.5 -fold increase in renal collagen IV (Fig. 3C, $* * * * P<0.0001)$ compared with control mice, in both glomerular (Fig. 3D, b vs. a, black arrows) and interstitial (Fig. 3D, b vs. a, red arrows) regions. In contrast, collagen IV protein levels in HFD + AC261-treated mice were lower than those in HFD-fed mice (Fig. 3D, c vs. b; Fig. 3C, $* * * * P<0.0001)$.
RARß2 Agonist-Treated Mice Exhibit Less Glomerular Basement Membrane Thickening. Thickening of glomerular basement membrane (GBM) is associated with easy stages of DN and strongly correlates with impaired renal function and albuminuria.

Using transmission electron microscopy (TEM), we next measured the mean GBM thickness in all groups, and we found an approximate 51\% increase in GBM thickness in HFD versus control mice (Fig. 4D; TEM, b vs. a, black cross; Fig. 4E). By PAS stain, capillary loops in HFD + AC261 mice were visually well defined, with less diffuse mesangial expansion into the GBM compared with HFD-fed mice (Fig. 2C, c vs. b, yellow arrows). GBM thickening in HFD + AC261 mice was not as pronounced as in HFD-fed mice and was visually more consistent with what we observed in controls (Fig. 2C, PAS, c vs. b and a, yellow arrows). By TEM ultrastructural analyses, we determined that AC261 treatment of HFD-fed mice resulted in approximately $22 \%$ less GBM thickening compared with non-drug-treated HFD mice (Fig. 4D, TEM, c vs. b, black cross; Fig. 4E). Taken together, these data show that the histologic changes in TEC vacuolization and glomerular 

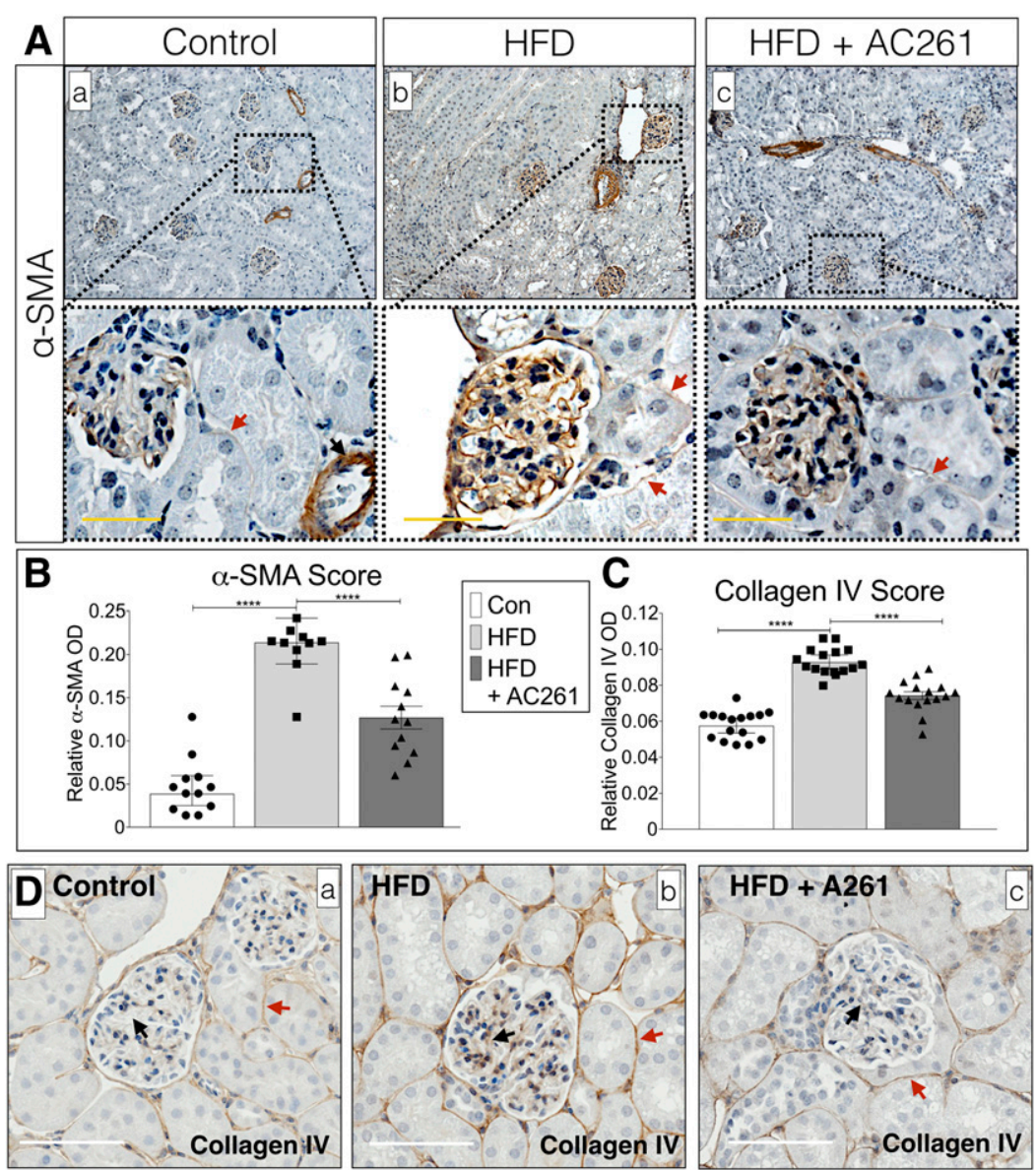

Fig. 3. $\operatorname{RAR} \beta 2$ agonist-treated mice show lower renal $\alpha$-SMA and type IV collagen resulting from a HFD. (A) $(\mathrm{a}-\mathrm{c})$ Representative images of $\alpha$-SMA IHC performed on renal sections from mice described in Fig. 1A with control mice $(n=3)$, (HFD, $n=3)$ and (HFD + AC261, $n=3)$. Original magnification, $100 \times$; scale bar, $50 \mu \mathrm{m}$; inset dotted field, magnification, $400 \times$, Scale bar, $100 \mu \mathrm{m}$. (B) $\alpha$-SMA IHC staining optical density (OD) determined in all mice from (A) and as described in Materials and Methods. (C) Collagen IV IHC staining OD score in all mice from (A) and as described in Materials and Methods. (D) Representative images of collagen IV IHC performed on renal sections from all mice described (A). Original magnification, $200 \times$; scale bar, $50 \mu \mathrm{m}$. Histogram individual data points represent the score of each slide analyzed per mouse as described in Materials and Methods. Error bars represent \pm S.D. of the mean of each group with $* * * * P<0.0001$. hypertrophy are consistent with the reductions in proteinuria (Fig. 1, E and F), and thus an anti-DN effect of AC261 in HFD-fed mice.

TEM Renal Ultrastructural Analysis. Analysis of TEM images of renal sections showed that, compared with control mice that exhibited normal glomerular filtration barrier (GFB) morphology (i.e., numerous interdigitating podocyte foot processes; Fig. 4A, red arrows, separated by filtration slits, Fig. 4A, black asterisks), HFD-fed mice had clear evidence of podocyte injury marked by podocyte foot process collapse and effacement (Fig. 4B vs. Fig. 4A, TEM, red arrows; Fig. 4D, TEM, b, red arrow), a reduction in podocyte foot process density (Fig. $4 \mathrm{~F}$, $* * * P<0.001)$, and a clear decrease in filtration slits across the GFB (Fig. 4B, black asterisks). HFD-fed mice exhibited lipid vacuoles in both podocyte foot processes and endothelial cells (ECs) (Fig. 4, yellow arrows), prominent EC injury with evidence of detachment and collapse from the basement membrane (Fig. 4B, white arrows), and reductions in EC fenestrations in the GFB (Fig. 4B vs. Fig. 4A, black arrows). By TEM ultrastructural renal evaluation, we found that, compared with kidneys of HFD-fed mice, the kidneys of HFD + AC261-treated mice showed diminished podocyte injury, with less foot process effacement (Fig. 4C vs. Fig. 4B, red arrows), a 1.0-fold increase in podocyte foot process density (Fig. $4 \mathrm{~F}, * * * P<0.001$ ), and filtration slits that more closely resembled those in the controls (Fig. $4 \mathrm{C}$ vs. Fig. $4 \mathrm{~A}$, black asterisks). By TEM analysis we also showed that, compared with HFD-fed mice, HFD + AC261-treated mice showed diminished EC injury indicated by decreased identification of EC collapse (Fig. 4C vs. Fig. 4B, white arrows), increased EC fenestrations (Fig. 4C vs. Fig. 4B, black arrows), and fewer EC lipid vacuoles (Fig. 4C vs. Fig. 4B, yellow arrows).

RARß2 Agonist Preserves Podocytes in HFD-Fed Mice. Podocytes form a portion of the GFB (Abrahamson, 2012; Nagata, 2016), and podocyte injury and effacement occur in the progression of DN (Nakamura et al., 2000; Nagata, 2016). Given the evidence from our TEM ultrastructural analysis that AC261 mitigated podocyte foot process effacement and increased podocyte density in the GFB of HFD-fed mice (Fig. 4B vs. Fig. 4, C and F), we next asked whether AC261 treatment affected the expression of podocin, a key protein in the foot process slit diaphragm structure where it is part of a scaffold complex that is essential in maintaining GFB function (Kawachi et al., 2006) and in preventing foot process effacement and loss (Kawachi et al., 2006; Nagata, 2016). Podocin and other slit-diaphragm proteins were reduced in animal DN models (Nakamura et al., 2000), human DN (Dronavalli et al., 2008), and other nephropathies (Johnstone and Holzman, 2006). Control mice showed prominent GBM podocin-positive areas, with some podocin expression observed in the mesangium membrane outlines (Fig. 5A, a, red arrows; Fig. 5B). Consistent with the presence of proteinuria (Fig. 1, E and F), GBM and mesangial podocin staining was thinner and fainter in HFD-fed mice (Fig. 5A, b, red arrows; Fig. 5B, ****P< 0.001). HFD + AC261-treated mice had immunopositive podocin regions in the GBM and mesangium that were similar to those observed in control mice (Fig. 5A, c, red arrows; Fig. 5B, **** $P<0.001$ ). 

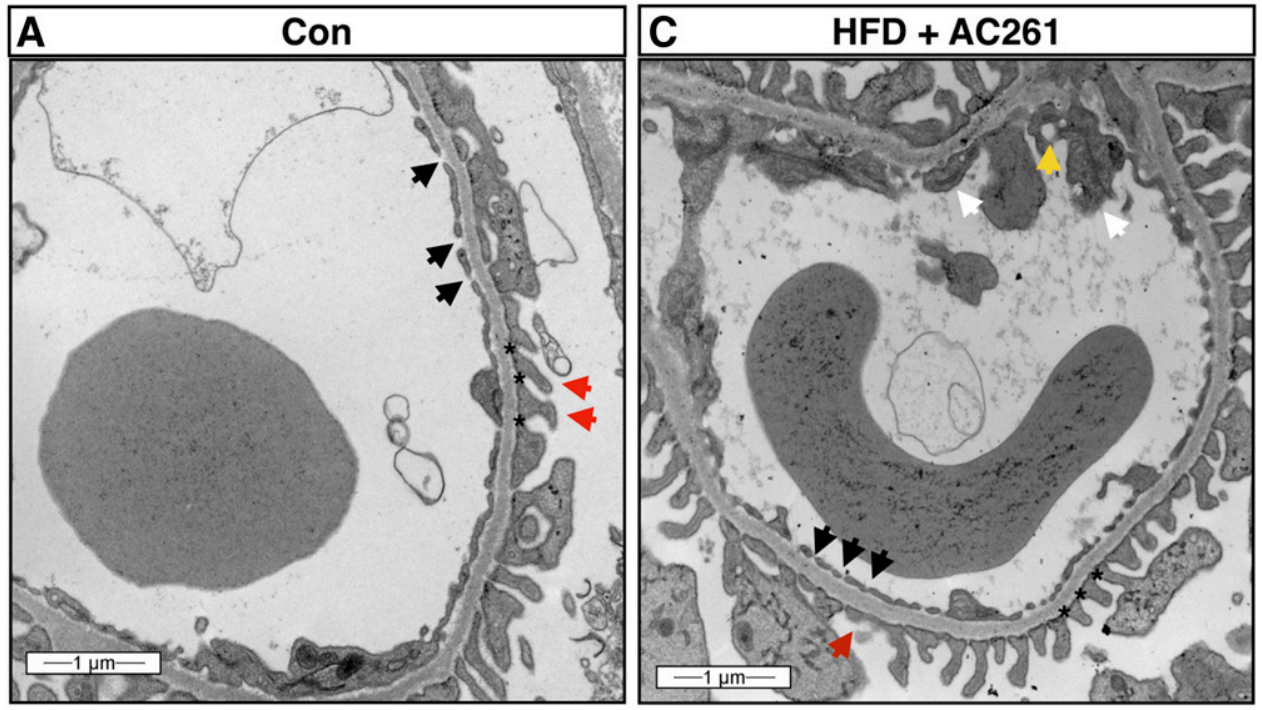

Fig. 4. Less podocyte effacement, glomerular basement membrane thickening, and ultrastructural renal lesions in retinoic acid receptor $\beta 2$ (RAR $\beta 2)$ agonist-treated mice. (A-C) Representative transmission electronic microscopic (TEM) images of glomeruli from mice described in Fig. 1A with control mice $(n=3)$, (HFD, $n=3)$, and (HFD+AC261, $n=3$ ). Original magnification, $20,000 \times$; Scale bar, $1 \mu \mathrm{m}$; Indicators: [black arrows $=$ capillary endothelial cell (EC) fenestrations; red arrows = podocyte foot process effacement and collapse; yellow arrows = podocyte and EC lipid droplets (LDs); white arrows = EC collapse; $*($ asterisks $)=$ podocyte foot process slit
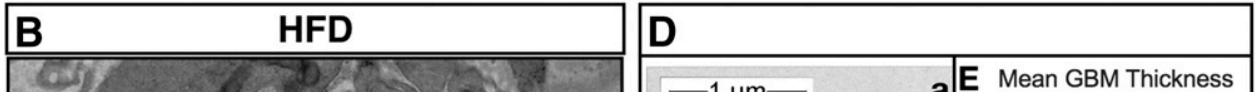
diaphragm; + (black cross) = capillary glomerular basement membrane]. (D) Representative TEM images of GBM from mice described in Fig. 1A. Original magnification, 20,000 ×; scale bar, $1 \mu \mathrm{m}$; Indicators: black cross $=$ GBM; red arrow $=$ podocyte foot process effacement and collapse. ( $\mathrm{E}$ and $\mathrm{F}$ ) Quantitation of GBM thickness and podocyte foot process density as described in Materials and Methods. Histogram individual data points represent the score of each slide analyzed per mouse as described in Materials and Methods. Errors bars represent \pm S.D. of the mean of each group with $* * P<0.01 ; * * * * P<0.0001$.

We also measured expression of WT1, a key transcription factor for renal development (Kreidberg et al., 1993), that in the adult kidney is not only detected in mature podocytes (Palmer et al., 2001) but is also expressed in podocyte progenitors as major regulator of podocyte development during renal organogenesis (Kreidberg et al., 1993). We detected WT1immunopositive nuclei in podocytes of control mice (Fig. 5A, d, red arrows; Fig. 5C) and, similar to the observed podocin staining pattern, we observed a smaller proportion of WT1-positive nuclei in HFD-fed mice compared with controls (Fig. 5A, e vs. day, red arrows; Fig. $5 \mathrm{C}, * * * P<0.001)$. In contrast, WT1 protein in HFD + AC261-treated mice was similar to that detected in controls (Fig. 5A, fvs. day, red arrows; Fig. 5C), with an increased number of WT1-positive nuclei compared with HFD mice (Fig. 5A, f vs. e, red arrows; Fig. 5C, $* * P<0.001$ ).

RARß2 Agonist Modulation of Renal and PodocyteSpecific Gene Expression in HFD-Fed Mice. We next measured relative mRNA levels of WT1, podocin, and three other podocyte-specific genes nephrin, podocalyxin, and synaptopodin, in renal cortex tissue from a HFD-DN cohort of mice using gene-specific primers (Supplemental Table 1) and q-PCR. We found that, similar to our IHC results, relative renal mRNA levels of WT1 and podocin in HFD-fed mice were reduced compared with control mice (Fig. $6 \mathrm{~A}$, $* * * P<0.001$; Fig. $6 \mathrm{~B}$, $* * P<0.01$ ), but in comparison with HFD-fed mice, HFD + AC261-treated mice had 2.6-fold $\left({ }^{*} P<0.05\right)$ and 2.7-fold higher $(* P<0.05)$ renal mRNA levels of $W T 1$ and podocin, respectively (Fig. 6, A and $\mathrm{B}$ ). Transcript levels of two other podocyte-specific genes, nephrin and podocalyxin, were unchanged across all treatments groups (Fig. 6, C and D). We did, however, detect a reduction in renal mRNA levels of the WT1-regulated gene and podocyte basement membrane anchorage-associated protein synaptopodin in HFD-fed mice compared with control mice (Fig. $6 \mathrm{E},{ }^{*} P<0.05$ ) and 2.0 -fold higher mRNA levels of synaptopodin in HFD + AC261-treated compared with HFD-fed mice (Fig. $6 \mathrm{E},{ }^{*} P<0.05$ ).

We next measured renal mRNA levels of key mediators of the renal renin-angiotensin system, including renin, and angiotensin I-converting enzymes 1 and 2 (Ace1 and Ace2) to examine if the anti-DN effects of AC261 involve any renal hemostatic changes. Increases in renal transcripts of Ace have been reported in cases of human DN (Konoshita et al., 2006); however, consistent with a previously published rat HFD model of DN (Tain et al., 2017), we did not detect significant 

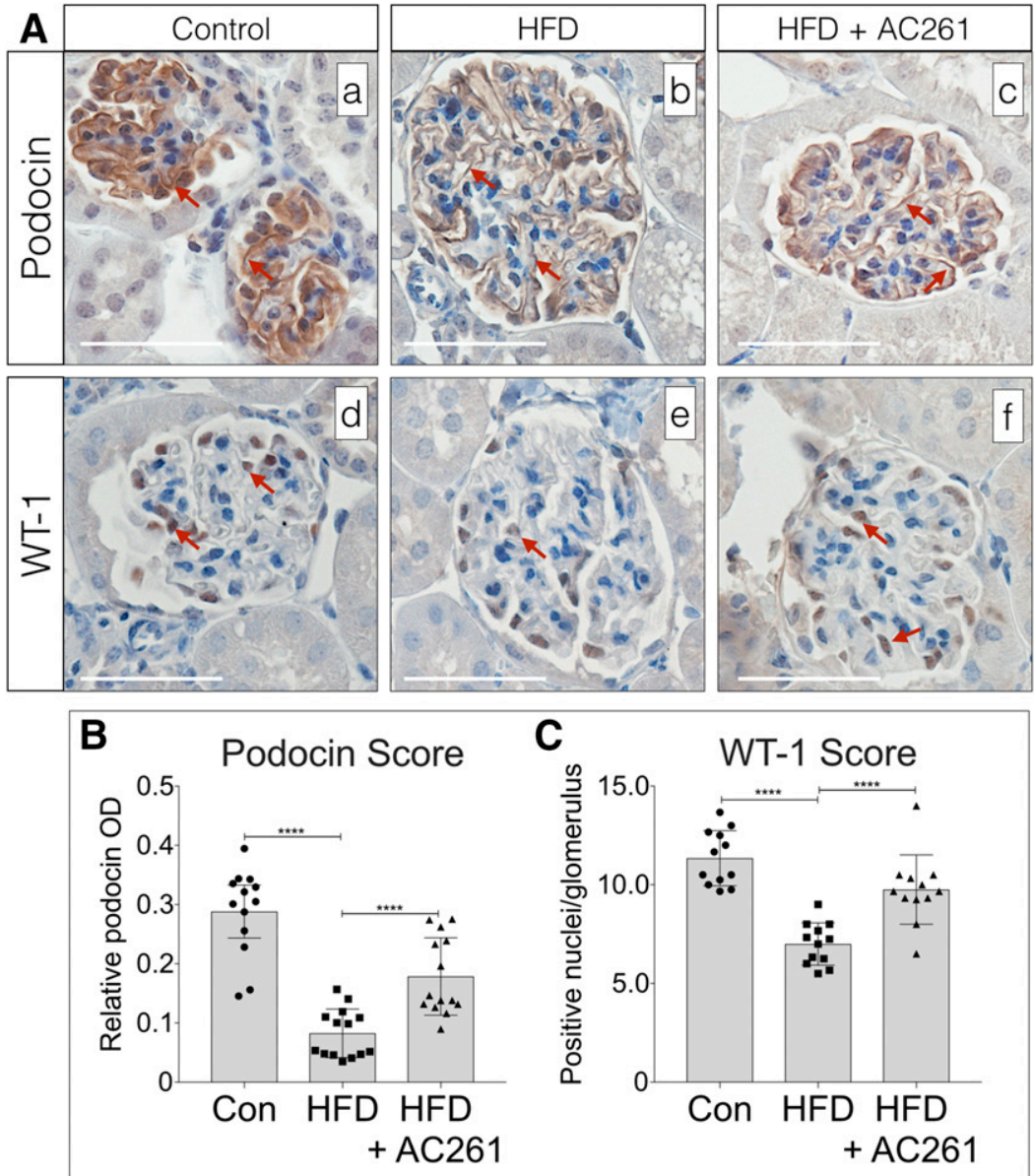

Fig. 5. Effects of RAR $\beta 2$ agonist on podocin and WT1 protein expression. (A) Representative images of podocin (membranous positivity) (a-c), and WT1 (nuclear positivity) (d-f) IHC performed on renal sections from mice described in Fig. 1A with control mice $(n=4)$, (HFD, $n=4)$ and (HFD + AC261, $n=4)$. Original magnification, $400 \times$; scale bar, $100 \mu \mathrm{m}$. (B and C) Podocin and WT1 IHC staining optical density (OD) and positive glomerular cell quantitation of all mice from (A) and as described in Materials and Methods. Histogram individual data points represent the score of each slide analyzed per mouse as described in Materials and Methods. Errors bars represent \pm S.D. of the mean of each group with $* * * * P<0.0001$.

changes in renal mRNA transcript levels of Ren, Ace1, and Ace 2 in HFD-fed or HFD + AC261-treated mice compared with control mice (Fig. 6, F-H).

There is some evidence that in the adult kidney, renal developmental pathways regulated by WT1 and RA may contribute preservation and maintenance of mature podocytes and podocyte progenitors in the healthy kidney and in response to renal injury (Sagrinati et al., 2006; Dong et al., 2015; Lasagni et al., 2015). Therefore, we next measured renal transcript mRNA levels of $B M P 7, \operatorname{Pax} 2$, and $M a f B$, three direct transcriptional targets of WT1 in podocyte progenitors during renal development (Hartwig et al., 2010), and Ret, a retinoid regulated gene critical to nephrogenesis (Batourina et al., 2001), to determine whether the anti-DN effect of AC261 involves modulation of $\mathrm{WT} 1$ or retinoidmediated podocyte progenitor or renal developmental pathways. Our q-PCR analysis showed that relative mRNA levels of BMP7, Pax2, MafB, and Ret were unchanged across all experimental groups (Fig. 6, I-L). These q-PCR data demonstrate that the anti-DN properties of AC261 do not involve activation of regenerative, or fetal retinoid-mediated developmental pathways.

RARß2 Agonist Modulation of Renal Vitamin A-Specific Genes in HFD-Fed Mice. To examine changes to retinoidmediated pathways, we next measured renal transcript levels of retinoid relevant genes, including $R A R \alpha, R A R \beta 2, R A R \gamma$, cellular retinoid binding protein 1 (CRBP1), aldehyde dehydrogenase, member 1a2 (ALDH1A2) and cytochrome P-450 enzyme (CYP26A1). RARß2 (Gillespie and Gudas, 2007), CRBP1 (Smith et al., 1991) and Cyp26a1 (Ray et al., 1997) have retinoic acid responsive elements (RAREs) in their promoters, and therefore transcript levels of these genes provide a reliable indicator of tissue retinoid signaling.

Our q-PCR analyses showed that renal transcript levels of $R A R \alpha$ were unchanged across all groups (Fig. 6M); however, transcripts of $R A R \beta 2, R A R \gamma$, and $C R B P 1$ were reduced in HFD-fed mice compared with controls (Fig. 6, N-P, ${ }^{*} P<0.05$ ). Renal transcripts of $A L D H 1 A 2$ were unchanged across all groups (Fig. 6Q), and, compared with control mice, mean renal levels of CYP26A1 mRNA were $\sim 2.0$-fold lower in HFD-fed mice; however, these differences were not statistically significant (Fig. $6 \mathrm{R}$, ns, $P>0.05$ ).

In HFD + AC261-treated mice, renal transcripts of $R A R \beta 2$ were also reduced compare with controls (Fig. $6 \mathrm{~N}$, $* P<0.05)$ but higher $(\sim 2.5$-fold) (Fig. $6 \mathrm{~N}, * P<0.05)$ than renal $R A R \beta 2$ transcript levels of HFD-fed mice. Compared with controls, renal transcript levels of $R A R \gamma$ and $C R B P 1$ were unchanged in HFD + AC261-treated mice (Fig. 6, O and $\mathrm{P}$ ) but, similar to $R A R \beta 2, R A R \gamma$, and $C R B P 1$, transcript levels were significantly higher $(\sim 1.8$ - and $\sim 2.3$-fold respectively) than the levels of these genes detected in HFD-fed mice (Fig. 6, $\mathrm{O}$ and $\mathrm{P},{ }^{*} P<0.05$ ). Similarly, renal transcript levels of CYP26A1 in HFD + AC261-treated mice were 2.3fold higher than in HFD-fed mice; however, these differences did not reach the level of statistical significance (Fig. 6R, ns, $P>0.05)$. 

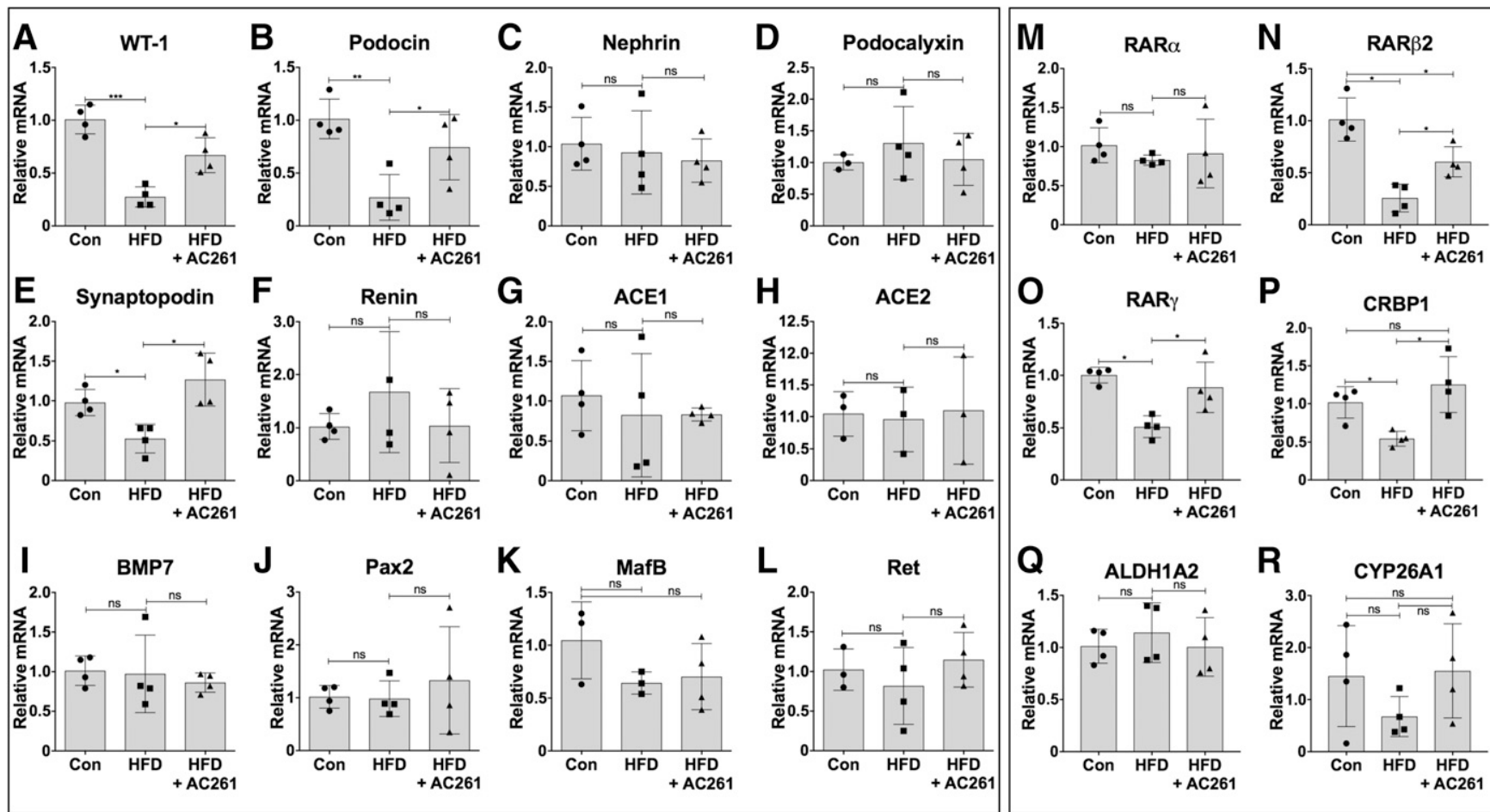

Fig. 6. Modulation of renal, podocyte, and vitamin A-specific genes by a HFD and RAR $\beta 2$ agonist. Quantitative RT-PCR measurements of relative renal cortex tissue transcript levels of podocyte-specific genes from Wt C57BL/6 male mice fed either chow or HFD diets with and without the RAR $\beta$ agonist (control mice, $n=4)$, (HFD, $n=4)$, and (HFD + AC261, $n=4)$ as described in the Materials and Methods. Relative renal mRNA levels of: (A) WT-1, (B) podocin (Nphs2), (C) nephrin (Nphs1), (D) podocalyxin (Podxl), (E) synaptopodin (Synpo), (F) renin (Ren), (G) Ace1, (H) Ace2), (I) bone morphogenetic protein 7 (BMP7), (J) paired box protein Pax-2 (Pax2), (K) MAF BZIP transcription factor B (MafB), (L) ret proto-oncogene (Ret), (M) RAR $\alpha$, (N) RAR 32 , (O) $R A R \gamma)$, (P) cellular retinoid binding protein 1 (CRBP1), (Q) aldehyde dehydrogenase, member 1a2 (ALDH1A2), (R) cytochrome P-450 enzyme (Cyp26a1). Relative fold mRNA levels were normalized to transcript levels of hypoxanthine guanine phosphoribosyl transferase (Hprt) and analyzed by the $\Delta, \Delta$ CT method as described in Materials and Methods. Histogram individual data points represent the mean of each mouse. Errors bars represent \pm S.D. of the mean of $(n=4)$ animals for each experimental group, with $* P<0.05 ; * * P<0.01 ; * * * P<0.001$; and ns $=$ not significant.

We next measured renal retinol (ROL) levels by HPLC. We found that, relative to control mice, HFD and HFD + AC261-treated mice showed approximately $23 \%$ and $44 \%$ reductions in renal ROL levels, respectively; however, these changes were not statistically significant (Supplemental Fig. $1 \mathrm{~A}, \mathrm{~ns}, P>0.05$ ), nor were renal ROL levels between HFD and HFD + AC261-treated mice (Supplemental Fig. 1A, ns, $P>0.05$ ). The trends are consistent with our previous research demonstrating that HFD-driven obesity is associated with tissue reductions in retinoids (Trasino et al., 2015). We also measured serum ROL by HPLC. These analyses showed that HFD and HFD + AC261-treated mice had elevations in serum retinol compared with control mice (Supplemental Fig. 1B, $* P<0.05$ ), but, as expected, and as we observed with renal ROL levels, no differences in serum ROL was detected between HFD and HFD + AC261-treated mice (Supplemental Fig. 1B, ns, $P>0.05)$.

RARß2 Agonist Improves Renal Lesions in BKS-db/ db Mice. Next, we examined whether AC261 affected histologic markers of DN in renal tissue from 16-week-old BKS-db/ db (BKS-db) mice treated with AC261 for 14 days. BKS-db mice spontaneously develop obesity and severe insulin resistance and recapitulate many of the renal histologic changes observed in human DN (Sharma et al., 2003; Brosius et al., 2009). BKS-db mice had significantly elevated BW and severe glucose intolerance compared with WT controls (Supplemental Fig. $\left.2, \mathrm{~A}-\mathrm{C},{ }^{* * *} P<0.001\right)$. BWs from BKS-db mice treated with
AC261 for 14 days were similar to the BW of untreated BKS-db mice (Supplemental Fig. 2A), but AC261 treatments did improve random glucose levels (Supplemental Fig. 2B, ** $P<0.01$ ), glucose tolerance, and area under the curve glucose levels (Supplemental Fig. $2, \mathrm{C}$ and D, $* P<0.05$ ). Our analyses of the pharmacokinetics of AC261 after a single dose show that this drug has excellent properties in terms of half-life and blood levels (Supplemental Fig. 3).

Compared with WT controls, BKS-db had 3.0-fold increased mean glomerular area (Fig. 7A, H\&E, b vs. a; Fig. 7B, ****P< 0.0001 ), evidence of moderate to severe thickening of the GBM, and prominent PAS-positive staining in the GBM of the capillary loops (Fig. 7A, PAS, e vs. day, red arrows; Fig. 7C, $* P<0.05)$. Similar to our findings in the HFD-DN cohort, by renal histology evaluation of BKS-db + AC261-treated mice, we found a mitigation of DN lesions compared with untreated BKS-db/db mice; BKS-db + AC261 treated mice showed 1.4-fold smaller mean glomerular area (Fig. 7A, H\&E, c vs. b; Fig. $7 \mathrm{~B}, * * * * P<0.0001)$ and less mesangial cellularity and expansion, marked by diminished PAS-positive material in the mesangium (Fig. 7A, PAS, f vs. e, red arrows; Fig. 7C $* P<$ 0.05 ) and capillary loop GBM (Fig. 7A, PAS, fvs. e, red arrows). Consistent with this, GBM thickness in BKS-db + AC261 mice was less pronounced than in untreated BKS-db mice and more closely resembled that seen in wt controls (Fig. 7A, PAS, f vs. e and d, red arrows). We next measured renal podocin protein by IHC and found that, compared with WT controls, untreated 

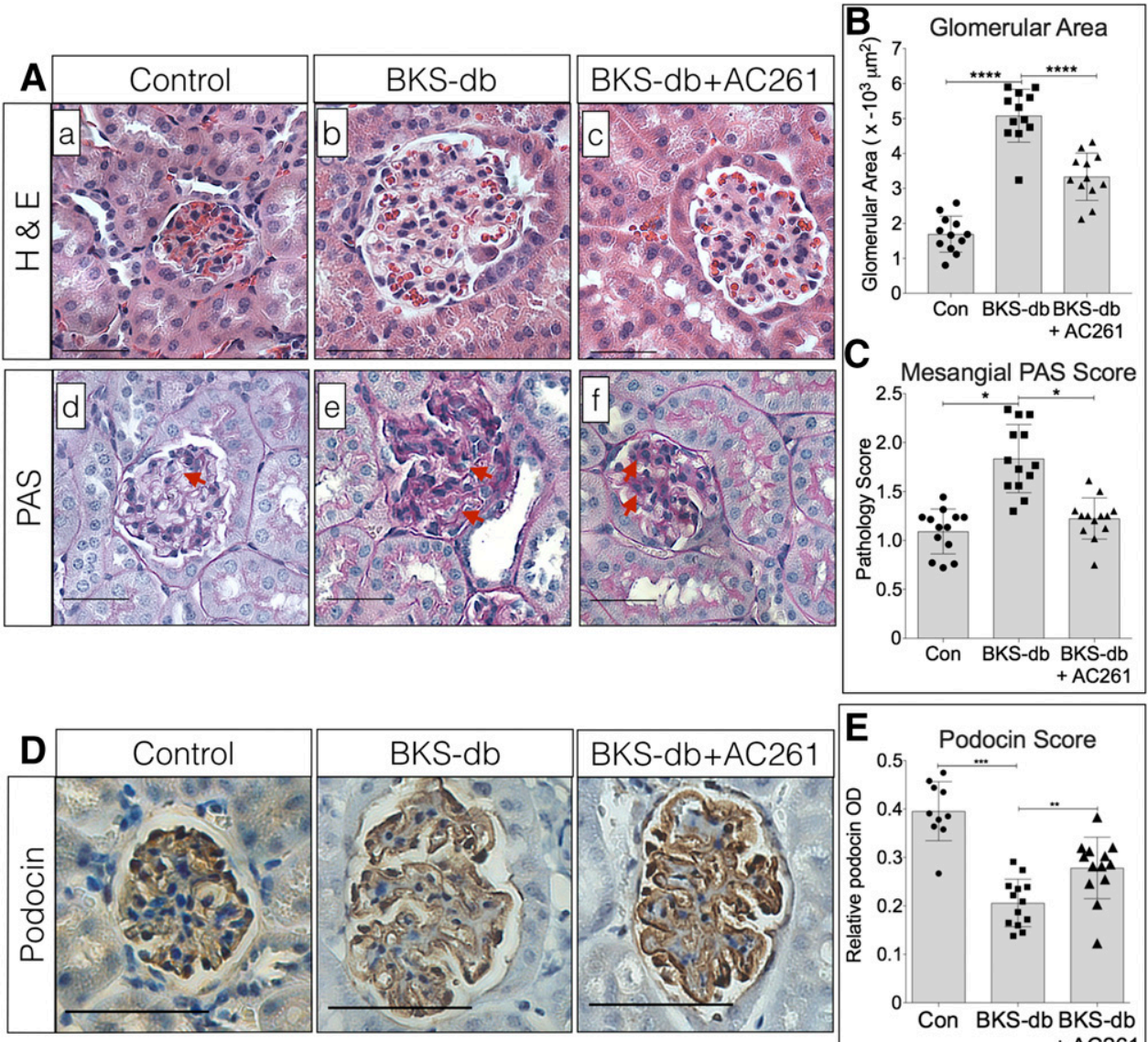

Fig. 7. RAR $\beta 2$ agonist-treated BKS-db/db mice show fewer DN lesions. (A) Representative images of $\mathrm{H} \& \mathrm{E}(\mathrm{a}-\mathrm{c})$, and PAS $(\mathrm{d}-\mathrm{f}$, red arrows $=$ capillary glomerular basement membrane thickening] stained renal sections from male $\mathrm{Wt}$ C57BL/6 (control, $n=4$ ) and 14-week-old BKS-db/ $\mathrm{db}$ (BKS-db, $n=3$ ) mice fed chow with and without the RAR $\beta 2$ agonist AC261066 (BKS-db + AC261, $n=3$ ) for 14 days. (B) Mean glomerular area $\left(-10^{3} \mu \mathrm{m}^{2}\right)$ of mice from (A), as described in Materials and Methods. (C) Mesangial expansion histology score of mice from (A) and as described in Materials and Methods. (D) Representative images of podocin IHC performed on renal sections from mice from (A). Original magnification, $400 \times$; scale bar, $100 \mu \mathrm{m}$. (E) Podocin IHC staining optical density (OD) quantitation of mice from (A) and as described in Materials and Methods. Histogram individual data points represent the score of each slide analyzed per mouse as described in Materials and Methods. Errors bars represent \pm S.D. of the mean of each group with $* P<0.05$ $* * P<0.01 ; * * * P<0.001$; **** $P<0.0001$.
BKS-db/db mice showed reduced podocin staining within the glomerular loops, mesangium, and GBM (Fig. 7, D and $\mathrm{E}, * * * P<0.001)$. In contrast to untreated BKS-db mice, BKS-db + AC261 mice had increased glomerular podocin protein (Fig. 7, D and E, $* * P<0.01$ ). Taken together, these data demonstrate that AC261 possesses therapeutic properties in a HFD-DN model and can inhibit development of DN histologic lesions in the BKS-db genetic model of DN.

\section{Discussion}

$\operatorname{RAR} \beta$ has four known isoforms (1-4) (Zelent et al., 1991; Gudas, 2011), with RAR $\beta 2$ considered the most prominent during kidney and vertebrate development (Zelent et al., 1991). We previously reported that AC261066, a highly selective agonist for RAR $\beta 2$ (Lund et al., 2005), possesses glucose-lowering properties in dietary and genetic models of obesity and T2D (Trasino et al., 2016a,b). In this study, we confirmed those findings and now report that AC261 diminishes the severity of urine albumin excretion and improves several structural and pathologic hallmarks of DN (Brosius et al., 2009; Deji et al., 2009) in HFD-fed mice, including glomerular hypertrophy, mesangial expansion, GBM thickening, and podocyte effacement.

To date, no studies have examined the renal protective effects of RA or RAR agonists in a HFD-driven model of DN or in BKS-db mice (Hummel et al., 1966), a frequently used genetic DN model that closely recapitulates a number of features of human DN (Sharma et al., 2003). Still, our findings are consistent with two published rodent DN studies by Kim et al. (2015) and Han et al. (2004), demonstrating that RA, a pan-RAR agonist, can mitigate DN progression, proteinuria, and podocyte expression of inflammatory markers in an inbred, genetic rat model of T2D (Kim et al., 2015), and a streptozotocin-induced model of DN (Han et al., 2004), respectively. Our findings elaborate on these RA-DN studies and collectively demonstrate that the therapeutic properties of AC261 are multimodal, affecting a numerous pathways relevant to $\mathrm{DN}$. Of these, the podocyte-preserving effect of AC261 may be the most relevant given the central role of podocyte injury in the pathogenesis of $\mathrm{DN}$ and several chronic kidney diseases (CKDs) (Johnstone and Holzman, 2006; Dronavalli et al., 2008). Furthermore, as we detected anti-DN effects of AC261 in both a dietary HFD and a genetic (chow-fed $\mathrm{BKS}-\mathrm{db}$ mice) obesity model of $\mathrm{DN}$, the renal protective properties of AC261 appear to be independent of diet (i.e., BKS-db mice develop DN on chow), which may have particular therapeutic relevance as DN cases disproportionally occur in adults with poorly controlled obesity owing to complex interaction of multiple causes, including genetic, dietary, and other environmental factors (Stenvinkel et al., 2013).

In the larger context of retinoid-CKD research, our findings highlight for the first time a potential role for RAR $\beta 2$ in CKD, whereas most retinoid-CKD research has focused on a role for $\operatorname{RAR} \alpha$ and the renal protective properties of $\operatorname{RAR} \alpha$ agonists (Lehrke et al., 2002; Ratnam et al., 2011; Zhong et al., 2011; Mallipattu and He, 2015; Dai et al., 2017). In our HFD-DN study, we did not detect changes to renal transcript levels of 
$R A R \alpha$ across all experimental groups, but we did measure significant reductions in $R A R \beta 2, R A R \gamma$, and $C R B P 1$ renal mRNA levels in HFD-fed mice. The trends of these findings are in agreement with a study by Ratnam et al. (2011), which demonstrated that renal levels of $\operatorname{RAR} \beta$, but not $\operatorname{RAR} \alpha$, are reduced in the CKD HIV-associated nephropathy, despite evidence that $\operatorname{RAR} \alpha$ and $\operatorname{RAR} \alpha$ agonists are relevant to both the pathogenesis and treatment of HIV-associated nephropathy (Ratnam et al., 2011; Dai et al., 2017) and other CKDs (Ratnam et al., 2011; Zhong et al., 2011; Mallipattu and He, 2015). Our data, coupled to the Ratnam et al. (2011) study, suggest that $\operatorname{RAR} \beta$ and its major isoform RAR $\beta 2$ potentially have an unappreciated role in CKD. Further support for this comes from a study demonstrating that the anti-CKD and podocyte-preserving effect of highly selective $\operatorname{RAR} \alpha$ agonists correlates with an increase in podocyte expression of RAR $\beta$ only (Zhong et al., 2011). Thus, it is our view that, not unlike during nephrogenesis (Batourina et al., 2001), where only mice lacking both RAR $\beta 2$ and RAR $\alpha$ develop postnatal renal malformations similar to those observed in VA-deficient adult mice (Batourina et al., 2001), a more nuanced, complex involvement of both RAR $\beta 2$ and RAR $\alpha$ likely occurs in adult renal biology and possibly in DN and other CKDs.

In this study, we detected a significantly elevated serum ROL, with concomitant reductions to renal retinol (ROL) levels and to RAR $\beta 2$ mRNA in HFD-fed mice compared with control mice. These findings are consistent with multiple lines of evidence of aberrant renal retinoid homeostasis in DN (Raila et al., 2007; Frey et al., 2008; Starkey et al., 2010; Jing et al., 2016) and our previous research (Trasino et al., 2015), in which we demonstrated that, even with sufficient dietary VA and elevated serum ROL, renal and numerous tissues have marked reductions in retinoid levels and retinoid signaling (Trasino et al., 2015), suggesting that obesity and its related disorders such as DN may lead to a state of tissue retinoid resistance (Trasino et al., 2015). It is noteworthy to highlight that renal retinoid resistance has been previously documented by our laboratory and others in human renal cancer (RC) (Guo et al., 2001), which show a distinct resistance to the therapeutic effects of retinoids owing to loss of RAR $\beta 2$ expression (reviewed in Tang and Gudas, 2011) and that reestablishing RAR 32 expression in RC (Touma et al., 2005) restores sensitivity to the antitumor effects of retinoids (Touma et al., 2005; Tang and Gudas, 2011). As RAR $\beta 2$-associated retinoid resistance has been documented in numerous cancers (Tang and Gudas, 2011), these data collectively suggest that RAR $\beta 2$ may be necessary for potentiation of global retinoid responsiveness in the kidney and other tissues. This hypothesis is further supported by studies of individuals with nonfunctional variants of RAR $\beta$ that develop Matthew-Wood syndrome (Srour et al., 2013), a rare genetic disorder that manifests as a severe VA-deficient state, also seen in individuals with mutations to STRA6, the receptor for RBP4 (Pasutto et al., 2007); it manifests as multiple organ malformations, including renal dysplasia (Pasutto et al., 2007) and resistance to the effects of exogenous RA and retinoids (Srour et al., 2013).

Whether RAR $\beta 2$ is involved in the altered retinoid metabolism in DN and CKD remains unclear, as is the mechanism by which renal ROL, retinoid homeostasis, and RAR signaling are altered in obesity and DN (Raila et al., 2007; Frey et al., 2008; Starkey et al., 2010; Jing et al., 2016). Nevertheless, if, as in RC, RAR $\beta$ is necessary for cellular RA responsiveness in $\mathrm{DN}$ and $\mathrm{CKD}$, our data demonstrating significantly higher renal mRNA levels of $R A R \beta 2, R A R \gamma, C R B P 1$ in HFD + AC261-treated mice compared with HFD-fed mice are noteworthy and collectively suggest that AC261 treatment engages retinoid pathways and prevents or reverses the reductions of renal retinoid signaling in HFD-fed mice. Compared with HFD-fed mice, we did not detect changes to renal or serum ROL in HFD + AC261-treated mice, suggesting that AC261 may facilitate the utilization of existing renal VA pools or directly transduce retinoid signaling as a RAR $\beta 2$-selective agonist without raising tissue levels of VA or affected wholebody retinoid status. This may be one of the mechanisms by which AC261 discharges its podocyte-preserving effect, as podocytes are highly dependent on and sensitive to maintaining endogenous retinoid signaling for function and in response to injury (Suzuki et al., 2003; Peired et al., 2013). These data warrant further studies to determine whether AC261 can potentiate the effects of exogenous retinoids and selective RAR $\alpha$ agonists on podocyte function and responses in $\mathrm{DN}$ and other CKDs. In the current study, we did not measure renal protein expression of RAR $\beta$ or RAR $\beta 2$, as validation studies of commercially available anti-mouse $\operatorname{RAR} \beta$ and RAR $\beta 2$ antibodies performed in our laboratory demonstrated a lack of specificity (unpublished reults).

We previously demonstrated that AC261 possesses lipidlowering properties in the kidney and other tissues in a HFDinduced T2D mouse model (Trasino et al., 2016a), and the current study expands on those findings and demonstrates that AC261 treatment results in less renal lipid droplet (LD) accumulation in podocytes and endothelial cells (EC), two cell types central to renal function and renal pathology in DN (Johnstone and Holzman, 2006; Dronavalli et al., 2008). Excessive renal LDs have been reported in human obesity, $\mathrm{DN}$, and other renal disease (Bobulescu et al., 2014; HermanEdelstein et al., 2014); as such, the "lipotoxicity" hypothesis of DN (reviewed in Bobulescu, 2010; Herman-Edelstein et al., 2014)) is supported by convincing evidence that ectopic renal LDs can initiate renal inflammatory and fibrotic responses that contribute to podocyte injury and loss (Bobulescu, 2010; Herman-Edelstein et al., 2014). Thus, the concomitant lower LD accumulation and decreases in effacement and injury in podocytes and ECs in HFD + AC261-treated mice compared with HFD-fed mice may be mechanistically related as podocytes and ECs synthesize and maintain components of the protein meshwork of the glomerular basement membrane (Abrahamson, 2012).

As the molecular pathogenesis of T2D and DN is intimately intertwined, and as podocytes are insulin-sensitive and hyperglycemia can induce podocyte injury (Coward and Saleem, 2011; Jain et al., 2011), we recognize that additional studies using mouse models with tissue and/or cell-specific $\operatorname{RAR} \beta$ and $\operatorname{RAR} \beta 2$ ablation are warranted to determine whether the therapeutic effects of AC261 in the kidney result from direct drug actions on several renal cell types or via indirect effects related to AC261's glucose-lowering properties. Clinical data, however, show that intensive glycemic and hypertension control has limited therapeutic effectiveness for DN (Parving et al., 2012; Fried et al., 2013; Gentile et al., 2014; Hajhosseiny et al., 2014). Additional studies are also needed to determine whether AC261 can reverse renal damage associated with $\mathrm{DN}$ since in this work we measured the ability of the drug to inhibit the development of DN. 
Although these results are promising, we recognize that one of the limitations of this preclinical study is the number of mice used. Future studies using larger cohorts of mice to measure the effects of AC261 on clinical and molecular pathways related to DN are planned. Nevertheless, given the lack of Food and Drug Administration-approved DN therapies, from a drugdevelopment perspective, these proof-of-concept preclinical studies of the therapeutic properties of the RAR $\beta 2$ agonist AC261 are promising, as AC261 is orally bioavailable (Lund et al., 2005; Trasino et al., 2016b), does not result in unwanted weight gain in the mouse models, and does not show any observable adverse effects in acute or long-term administration in rodents (Trasino et al., 2016a,b).

\section{Acknowledgments}

We thank Viral Patel for urine albumin and creatinine analysis, the Gudas laboratory members for data discussions, Daniel Stummer for editorial assistance, and the Weill Cornell Electron Microscopy Core Laboratory for TEM tissue processing, image acquisition, and analysis.

\section{Authorship Contributions}

Participated in research design: Trasino, Tang, Shevchuk, Choi, Gudas.

Conducted experiments: Trasino, Tang, Gudas.

Performed data analysis: Trasino, Tang, Shevchuk, Choi, Gudas.

Wrote or contributed to the writing of the manuscript: Trasino, Tang, Shevchuk, Choi, Gudas.

\section{References}

Abrahamson DR (2012) Role of the podocyte (and glomerular endothelium) in building the GBM. Semin Nephrol 32:342-349.

Alsaad KO and Herzenberg AM (2007) Distinguishing diabetic nephropathy from other causes of glomerulosclerosis: an update. J Clin Pathol 60:18-26.

Anderson RJ, Ray CJ, and Hattler BG (1998) Retinoic acid regulation of renal tubular epithelial and vascular smooth muscle cell function. J Am Soc Nephrol 9: $773-781$.

Batourina E, Choi C, Paragas N, Bello N, Hensle T, Costantini FD, Schuchardt A, Bacallao RL, and Mendelsohn CL (2002) Distal ureter morphogenesis depends on epithelial cell remodeling mediated by vitamin A and Ret. Nat Genet 32:109-115.

Batourina E, Gim S, Bello N, Shy M, Clagett-Dame M, Srinivas S, Costantini F, and Mendelsohn C (2001) Vitamin A controls epithelial/mesenchymal interactions through Ret expression. Nat Genet 27:74-78.

Blomhoff R, Green MH, Berg T, and Norum KR (1990) Transport and storage of vitamin A. Science 250:399-404.

Bobulescu IA (2010) Renal lipid metabolism and lipotoxicity. Curr Opin Nephrol Hypertens 19:393-402.

Bobulescu IA, Lotan Y, Zhang J, Rosenthal TR, Rogers JT, Adams-Huet B, Sakhaee $\mathrm{K}$, and Moe OW (2014) Triglycerides in the human kidney cortex: relationship with body size. PLoS One 9:e101285.

Bollig F, Perner B, Besenbeck B, Köthe S, Ebert C, Taudien S, and Englert C (2009) A highly conserved retinoic acid responsive element controls wt1a expression in the zebrafish pronephros. Development 136:2883-2892.

Brosius FC III, Alpers CE, Bottinger EP, Breyer MD, Coffman TM, Gurley SB, Harris RC, Kakoki M, Kretzler M, Leiter EH, et al. Animal Models of Diabetic Complications Consortium (2009) Mouse models of diabetic nephropathy. J Am Soc Nephrol 20:2503-2512.

Chambon $\mathrm{P}$ (1996) A decade of molecular biology of retinoic acid receptors. FASEB J 10:940-954.

Chiba T, Skrypnyk NI, Skvarca LB, Penchev R, Zhang KX, Rochon ER, Fall JL, Paueksakon P, Yang H, Alford CE, et al. (2016) Retinoic acid signaling coordinates macrophage-dependent injury and repair after AKI. J Am Soc Nephrol 27:495-508

Cook HT (2010) The origin of renal fibroblasts and progression of kidney disease. Am J Pathol 176:22-24.

Couchman JR, Beavan LA, and McCarthy KJ (1994) Glomerular matrix: synthesis, turnover and role in mesangial expansion. Kidney Int 45:328-335.

Coward RJ and Saleem MA (2011) Podocytes as a target of insulin. Curr Diabetes Rev 7:22-27.

Dai Y, Chen A, Liu R, Gu L, Sharma S, Cai W, Salem F, Salant DJ, Pippin JW, Shankland SJ, et al. (2017) Retinoic acid improves nephrotoxic serum-induced glomerulonephritis through activation of podocyte retinoic acid receptor $\alpha$. Kidney Int 92:1444-1457.

de Boer IH, Rue TC, Hall YN, Heagerty PJ, Weiss NS, and Himmelfarb J (2011) Temporal trends in the prevalence of diabetic kidney disease in the United States. JAMA 305:2532-2539.

Deegens JK, Dijkman HB, Borm GF, Steenbergen EJ, van den Berg JG, Weening JJ, and Wetzels JF (2008) Podocyte foot process effacement as a diagnostic tool in focal segmental glomerulosclerosis. Kidney Int 74:1568-1576.
Deji N, Kume S, Araki S, Soumura M, Sugimoto T, Isshiki K, Chin-Kanasaki M, Sakaguchi M, Koya D, Haneda M, et al. (2009) Structural and functional changes in the kidneys of high-fat diet-induced obese mice. Am J Physiol Renal Physiol 296 : F118-F126.

Dong L, Pietsch S, Tan Z, Perner B, Sierig R, Kruspe D, Groth M, Witzgall R, Gröne HJ, Platzer M, et al. (2015) Integration of cistromic and transcriptomic analyses identifies Nphs2, mafb, and Magi2 as Wilms' tumor 1 target genes in podocyte differentiation and maintenance. J Am Soc Nephrol 26:2118-2128.

Dronavalli S, Duka I, and Bakris GL (2008) The pathogenesis of diabetic nephropathy. Nat Clin Pract Endocrinol Metab 4:444-452.

Frey SK, Nagl B, Henze A, Raila J, Schlosser B, Berg T, Tepel M, Zidek W, Weickert MO, Pfeiffer AF, et al. (2008) Isoforms of retinol binding protein 4 (RBP4) are increased in chronic diseases of the kidney but not of the liver. Lipids Health Dis 7:29.

Fried LF, Emanuele N, Zhang JH, Brophy M, Conner TA, Duckworth W, Leehey DJ, McCullough PA, O'Connor T, Palevsky PM, et al.; VA NEPHRON-D Investigators (2013) Combined angiotensin inhibition for the treatment of diabetic nephropathy. N Engl J Med 369:1892-1903.

Gentile G, Mastroluca D, Ruggenenti P, and Remuzzi G (2014) Novel effective drugs for diabetic kidney disease? or not? Expert Opin Emerg Drugs 19:571-601.

Gilbert T (2002) Vitamin A and kidney development. Nephrol Dial Transplant 17 (Suppl 9):78-80.

Gillespie RF and Gudas LJ (2007) Retinoid regulated association of transcriptional co-regulators and the polycomb group protein SUZ12 with the retinoic acid response elements of Hoxa1, RARbeta(2), and Cyp26A1 in F9 embryonal carcinoma cells. J Mol Biol 372:298-316.

Gudas LJ (2012) Emerging roles for retinoids in regeneration and differentiation in normal and disease states. Biochim Biophys Acta 1821:213-221.

Guo M, Ricardo SD, Deane JA, Shi M, Cullen-McEwen L, and Bertram JF (2005) A stereological study of the renal glomerular vasculature in the $\mathrm{db} / \mathrm{db}$ mouse model of diabetic nephropathy. J Anat 207:813-821.

Guo X, Nanus DM, Ruiz A, Rando RR, Bok D, and Gudas LJ (2001) Reduced levels of retinyl esters and vitamin A in human renal cancers. Cancer Res 61:2774-2781.

Hajhosseiny R, Khavandi K, Jivraj N, Mashayekhi S, Goldsmith DJ, and Malik RA (2014) Have we reached the limits for the treatment of diabetic nephropathy? Expert Opin Investig Drugs 23:511-522.

Han SY, So GA, Jee YH, Han KH, Kang YS, Kim HK, Kang SW, Han DS, Han JY, and Cha DR (2004) Effect of retinoic acid in experimental diabetic nephropathy. Immunol Cell Biol 82:568-576.

Hartwig S, Ho J, Pandey P, Macisaac K, Taglienti M, Xiang M, Alterovitz G, Ramoni M, Fraenkel E, and Kreidberg JA (2010) Genomic characterization of Wilms' tumor suppressor 1 targets in nephron progenitor cells during kidney development. Development 137:1189-1203.

Herman-Edelstein M, Scherzer P, Tobar A, Levi M, and Gafter U (2014) Altered renal lipid metabolism and renal lipid accumulation in human diabetic nephropathy. J Lipid Res 55:561-572.

Hummel KP, Dickie MM, and Coleman DL (1966) Diabetes, a new mutation in the mouse. Science 153:1127-1128

Jain S, De Petris L, Hoshi M, Akilesh S, Chatterjee R, and Liapis H (2011) Expression profiles of podocytes exposed to high glucose reveal new insights into early diabetic glomerulopathy. Lab Invest 91:488-498.

Jensen EB, Gundersen HJ, and Osterby R (1979) Determination of membrane thickness distribution from orthogonal intercepts. J Microsc 115:19-33.

Jing J, Isoherranen N, Robinson-Cohen C, Petrie I, Kestenbaum BR, and Yeung CK (2016) Chronic kidney disease alters vitamin A homeostasis via effects on hepatic RBP4 protein expression and metabolic enzymes. Clin Transl Sci 9:207-215.

Johnstone DB and Holzman LB (2006) Clinical impact of research on the podocyte slit diaphragm. Nat Clin Pract Nephrol 2:271-282.

Kang HM, Ahn SH, Choi P, Ko YA, Han SH, Chinga F, Park AS, Tao J, Sharma K Pullman J, et al. (2015) Defective fatty acid oxidation in renal tubular epithelial cells has a key role in kidney fibrosis development. Nat Med 21:37-46.

Kawachi H, Miyauchi N, Suzuki K, Han GD, Orikasa M, and Shimizu F (2006) Role of podocyte slit diaphragm as a filtration barrier. Nephrology (Carlton) 11:274-281.

Kim CS, Park JS, Ahn CW, and Kim KR (2015) All-trans retinoic acid has a potential therapeutic role for diabetic nephropathy. Yonsei Med $J$ 56:1597-1603.

Konoshita T, Wakahara S, Mizuno S, Motomura M, Aoyama C, Makino Y, Kawai Y, Kato N, Koni I, Miyamori I, et al. (2006) Tissue gene expression of reninangiotensin system in human type 2 diabetic nephropathy. Diabetes Care 29: 848-852

Kreidberg JA, Sariola H, Loring JM, Maeda M, Pelletier J, Housman D, and Jaenisch R (1993) WT-1 is required for early kidney development. Cell 74:679-691.

Krendel M, Kim SV, Willinger T, Wang T, Kashgarian M, Flavell RA, and Mooseker MS (2009) Disruption of Myosin 1e promotes podocyte injury. J Am Soc Nephrol 20: $86-94$

Kurien BT and Scofield RH (1999) Mouse urine collection using clear plastic wrap. Lab Anim 33:83-86.

Lasagni L, Angelotti ML, Ronconi E, Lombardi D, Nardi S, Peired A, Becherucci F Mazzinghi B, Sisti A, Romoli S, et al. (2015) Podocyte regeneration driven by renal progenitors determines glomerular disease remission and can $\mathrm{Be}$ pharmacologically enhanced. Stem Cell Reports 5:248-263.

Lazzeri E, Peired AJ, Lasagni L, and Romagnani P (2014) Retinoids and glomerular regeneration. Semin Nephrol 34:429-436.

Lehrke I, Schaier M, Schade K, Morath C, Waldherr R, Ritz E, and Wagner J (2002) Retinoid receptor-specific agonists alleviate experimental glomerulonephritis. Am J Physiol Renal Physiol 282:F741-F751.

Lelièvre-Pégorier M, Vilar J, Ferrier ML, Moreau E, Freund N, Gilbert T, and Merlet-Bénichou C (1998) Mild vitamin A deficiency leads to inborn nephron deficit in the rat. Kidney Int 54:1455-1462.

Livak KJ and Schmittgen TD (2001) Analysis of relative gene expression data using real-time quantitative PCR and the 2(-Delta Delta C(T)) Method. Methods 25: 402-408. 
Lu TC, Wang Z, Feng X, Chuang P, Fang W, Chen Y, Neves S, Maayan A, Xiong H, Liu Y, et al. (2008) Retinoic acid utilizes CREB and USF1 in a transcriptional feedforward loop in order to stimulate MKP1 expression in human immunodeficiency virus-infected podocytes. Mol Cell Biol 28:5785-5794.

Lund BW, Knapp AE, Piu F, Gauthier NK, Begtrup M, Hacksell U, and Olsson R (2009) Design, synthesis, and structure-activity analysis of isoform-selective retinoic acid receptor beta ligands. J Med Chem 52:1540-1545.

Lund BW, Piu F, Gauthier NK, Eeg A, Currier E, Sherbukhin V, Brann MR, Hacksell U, and Olsson R (2005) Discovery of a potent, orally available, and isoform-selective retinoic acid beta2 receptor agonist. J Med Chem 48 7517-7519.

Mallipattu SK and He JC (2015) The beneficial role of retinoids in glomerular disease. Front Med (Lausanne) 2:16

Manzano VM, Muñoz JC, Jiménez JR, Puyol MR, Puyol DR, Kitamura M, and Cazaña FJ (2000) Human renal mesangial cells are a target for the antiinflammatory action of 9-cis retinoic acid. Br J Pharmacol 131:1673-1683.

Mendelsohn C, Batourina E, Fung S, Gilbert T, and Dodd J (1999) Stromal cells mediate retinoid-dependent functions essential for renal development. Development 126:1139-1148.

Nagata M (2016) Podocyte injury and its consequences. Kidney Int 89:1221-1230.

Nakamura T, Ushiyama C, Suzuki S, Hara M, Shimada N, Ebihara I, and Koide H (2000) Urinary excretion of podocytes in patients with diabetic nephropathy. Nephrol Dial Transplant 15:1379-1383.

Palmer RE, Kotsianti A, Cadman B, Boyd T, Gerald W, and Haber DA (2001) WT1 regulates the expression of the major glomerular podocyte membrane protein Podocalyxin. Curr Biol 11:1805-1809.

Parving HH, Brenner BM, McMurray JJ, de Zeeuw D, Haffner SM, Solomon SD, Chaturvedi N, Persson F, Desai AS, Nicolaides M, et al.; ALTITUDE Investigator (2012) Cardiorenal end points in a trial of aliskiren for type 2 diabetes. $N$ Engl $J$ Med 367:2204-2213.

Pasutto F, Sticht H, Hammersen G, Gillessen-Kaesbach G, Fitzpatrick DR, Nürnberg G, Brasch F, Schirmer-Zimmermann H, Tolmie JL, Chitayat D, et al. (2007) Mutations in STRA6 cause a broad spectrum of malformations including anophthalmia, congenital heart defects, diaphragmatic hernia, alveolar capillary dysplasia, lung hypoplasia, and mental retardation. Am J Hum Genet 80:550-560.

Peired A, Angelotti ML, Ronconi E, la Marca G, Mazzinghi B, Sisti A, Lombardi D, Giocaliere E, Della Bona M, Villanelli F, et al. (2013) Proteinuria impairs podocyte regeneration by sequestering retinoic acid. J Am Soc Nephrol 24:1756-1768.

Perez A, Ramirez-Ramos M, Calleja C, Martin D, Namorado MC, Sierra G, RamirezRamos ME, Paniagua R, Sánchez Y, Arreola L, et al. (2004) Beneficial effect of retinoic acid on the outcome of experimental acute renal failure. Nephrol Dial Transplant 19:2464-2471.

Raila J, Henze A, Spranger J, Möhlig M, Pfeiffer AF, and Schweigert FJ (2007) Microalbuminuria is a major determinant of elevated plasma retinol-binding protein 4 in type 2 diabetic patients. Kidney Int 72:505-511.

Raila J, Willnow TE, and Schweigert FJ (2005) Megalin-mediated reuptake of retinol in the kidneys of mice is essential for vitamin A homeostasis. J Nutr 135 $2512-2516$.

Ratnam KK, Feng X, Chuang PY, Verma V, Lu TC, Wang J, Jin Y, Farias EF, Napoli JL, Chen N, et al. (2011) Role of the retinoic acid receptor- $\alpha$ in HIV-associated nephropathy. Kidney Int 79:624-634.

Ray WJ, Bain G, Yao M, and Gottlieb DI (1997) CYP26, a novel mammalian cytochrome $\mathrm{P} 450$, is induced by retinoic acid and defines a new family. $J$ Biol Chem 272:18702-18708.

Rosselot C, Spraggon L, Chia I, Batourina E, Riccio P, Lu B, Niederreither K, Dolle P, Duester G, Chambon P, et al. (2010) Non-cell-autonomous retinoid signaling is crucial for renal development. Development 137:283-292.

Sagrinati C, Netti GS, Mazzinghi B, Lazzeri E, Liotta F, Frosali F, Ronconi E, Meini C, Gacci M, Squecco R, et al. (2006) Isolation and characterization of multipotent progenitor cells from the Bowman's capsule of adult human kidneys. J Am Soc Nephrol 17:2443-2456.

Sastre C, Rubio-Navarro A, Buendía I, Gómez-Guerrero C, Blanco J, Mas S, Egido J, Blanco-Colio LM, Ortiz A, and Moreno JA (2013) Hyperlipidemia-associated renal damage decreases Klotho expression in kidneys from ApoE knockout mice. PLoS One 8:e83713.

Schaier M, Lehrke I, Schade K, Morath C, Shimizu F, Kawachi H, Grone HJ, Ritz E, and Wagner J (2001) Isotretinoin alleviates renal damage in rat chronic glomerulonephritis. Kidney Int 60:2222-2234.

Schindelin J, Arganda-Carreras I, Frise E, Kaynig V, Longair M, Pietzsch T, Preibisch S, Rueden C, Saalfeld S, Schmid B, et al. (2012) Fiji: an open-source platform for biological-image analysis. Nat Methods 9:676-682.

Sharma K, McCue P, and Dunn SR (2003) Diabetic kidney disease in the $\mathrm{db} / \mathrm{db}$ mouse. Am J Physiol Renal Physiol 284:F1138-F1144.

Smith FR and Goodman DS (1971) The effects of diseases of the liver, thyroid, and kidneys on the transport of vitamin A in human plasma. $J$ Clin Invest $\mathbf{5 0}$ $2426-2436$.

Smith WC, Nakshatri H, Leroy P, Rees J, and Chambon P (1991) A retinoic acid response element is present in the mouse cellular retinol binding protein I (mCRBPI) promoter. $E M B O J \mathbf{1 0}: 2223-2230$.
Srour M, Chitayat D, Caron V, Chassaing N, Bitoun P, Patry L, Cordier MP, CapoChichi JM, Francannet C, Calvas P, et al. (2013) Recessive and dominant mutations in retinoic acid receptor beta in cases with microphthalmia and diaphragmatic hernia. Am J Hum Genet 93:765-772.

Starkey JM, Zhao Y, Sadygov RG, Haidacher SJ, Lejeune WS, Dey N, Luxon BA Kane MA, Napoli JL, Denner L, et al. (2010) Altered retinoic acid metabolism in diabetic mouse kidney identified by $\mathrm{O}$ isotopic labeling and 2D mass spectrometry. PLoS One 5:e11095.

Stenvinkel P, Zoccali C, and Ikizler TA (2013) Obesity in CKD-what should nephrologists know? J Am Soc Nephrol 24:1727-1736.

Stratton IM, Adler AI, Neil HA, Matthews DR, Manley SE, Cull CA, Hadden D, Turner RC, and Holman RR (2000) Association of glycaemia with macrovascular and microvascular complications of type 2 diabetes (UKPDS 35): prospective observational study. BMJ 321:405-412.

Su B, Chen X, Zhong C, Guo N, He J, and Fan Y (2012) All-trans retinoic acid inhibits mesangial cell proliferation by up-regulating p21Waf1/Cip1 and p27Kip1 and down-regulating Skp2. J Nephrol 25:1031-1040.

Suzuki A, Ito T, Imai E, Yamato M, Iwatani H, Kawachi H, and Hori M (2003) Retinoids regulate the repairing process of the podocytes in puromycin aminonucleoside-induced nephrotic rats. J Am Soc Nephrol 14:981-991.

Szeto HH, Liu S, Soong Y, Seshan SV, Cohen-Gould L, Manichev V, Feldman LC, and Gustafsson T (2017) Mitochondria protection after acute ischemia prevents prolonged upregulation of IL-1 $\beta$ and IL-18 and arrests CKD. J Am Soc Nephrol 28 1437-1449.

Tain YL, Lin YJ, Sheen JM, Yu HR, Tiao MM, Chen CC, Tsai CC, Huang LT, and Hsu CN (2017) High fat diets sex-specifically affect the renal transcriptome and program obesity, kidney injury, and hypertension in the offspring. Nutrients 9 357-376.

Tang XH and Gudas LJ (2011) Retinoids, retinoic acid receptors, and cancer. Annu Rev Pathol 6:345-364.

Tervaert TW, Mooyaart AL, Amann K, Cohen AH, Cook HT, Drachenberg CB, Ferrario F, Fogo AB, Haas M, de Heer E, et al.; Renal Pathology Society (2010) Pathologic classification of diabetic nephropathy. J Am Soc Nephrol 21:556-563.

Touma SE, Goldberg JS, Moench P, Guo X, Tickoo SK, Gudas LJ, and Nanus DM (2005) Retinoic acid and the histone deacetylase inhibitor trichostatin a inhibit the proliferation of human renal cell carcinoma in a xenograft tumor model. Clin Cancer Res 11:3558-3566.

Trasino SE, Tang XH, Jessurun J, and Gudas LJ (2015) Obesity leads to tissue, but not serum vitamin a deficiency. Sci Rep 5:15893.

Trasino SE, Tang XH, Jessurun J, and Gudas LJ (2016a) A retinoic acid receptor $\beta 2$ agonist reduces hepatic stellate cell activation in nonalcoholic fatty liver disease. J Mol Med (Berl) 94:1143-1151.

Trasino SE, Tang XH, Jessurun J, and Gudas LJ (2016b) Retinoic acid receptor $\beta 2$ agonists restore glycaemic control in diabetes and reduce steatosis. Diabetes Obes Metab 18:142-151.

Uhlén M, Fagerberg L, Hallström BM, Lindskog C, Oksvold P, Mardinoglu A, Sivertsson A, Kampf C, Sjöstedt E, Asplund A, et al. (2015) Proteomics: tissuebased map of the human proteome. Science 347:1260419.

Valmadrid CT, Klein R, Moss SE, and Klein BE (2000) The risk of cardiovascular disease mortality associated with microalbuminuria and gross proteinuria in persons with older-onset diabetes mellitus. Arch Intern Med 160:1093-1100.

Vaughan MR, Pippin JW, Griffin SV, Krofft R, Fleet M, Haseley L, and Shankland SJ (2005) ATRA induces podocyte differentiation and alters nephrin and podocin expression in vitro and in vivo. Kidney Int 68:133-144.

Wagner J, Dechow C, Morath C, Lehrke I, Amann K, Waldherr R, Floege J, and Ritz E (2000) Retinoic acid reduces glomerular injury in a rat model of glomerular damage. J Am Soc Nephrol 11:1479-1487.

Wei P, Lane PH, Lane JT, Padanilam BJ, and Sansom SC (2004) Glomerular structural and functional changes in a high-fat diet mouse model of early-stage Type 2 diabetes. Diabetologia 47:1541-1549.

Weibel ER and Gomez DM (1962) A principle for counting tissue structures on random sections. J Appl Physiol 17:343-348.

Zelent A, Mendelsohn C, Kastner P, Krust A, Garnier JM, Ruffenach F, Leroy P, and Chambon $\mathrm{P}$ (1991) Differentially expressed isoforms of the mouse retinoic acid receptor beta generated by usage of two promoters and alternative splicing. EMBO J 10:71-81.

Zhang J, Pippin JW, Vaughan MR, Krofft RD, Taniguchi Y, Romagnani P, Nelson PJ, Liu ZH, and Shankland SJ (2012) Retinoids augment the expression of podocyte proteins by glomerular parietal epithelial cells in experimental glomerular disease. Nephron, Exp Nephrol 121:e23-e37.

Zhong Y, Wu Y, Liu R, Li Z, Chen Y, Evans T, Chuang P, Das B, and He JC (2011) Novel retinoic acid receptor alpha agonists for treatment of kidney disease. PLoS One 6:e27945.

Address correspondence to: Dr. Lorraine J. Gudas, Department of Pharmacology, Weill Cornell Medical College, 1300 York Avenue, New York, NY 10065. E-mail: ljgudas@med.cornell.edu 